NBER WORKING PAPER SERIES

\title{
CRISES AND GROWTH: A RE-EVALUATION
}

\author{
Romain Ranciere \\ Aaron Tornell \\ Frank Westermann \\ Working Paper 10073 \\ http://www.nber.org/papers/w10073
NATIONAL BUREAU OF ECONOMIC RESEARCH 1050 Massachusetts Avenue
Cambridge, MA 02138
October 2003

We thank Jess Benhabib, Sudipto Bhattacharya, Pierre Olivier Gourinchas, Thorvaldur Gylfason, Jürgen von Hagen, Lutz Hendricks, Fabrizio Perri, Joris Pinske, Franck Portier, Debraj Ray, Hans-Werner Sinn, Carolyn Sissoko, Jean Tirole, Jaume Ventura and seminar participants at Bonn, Haravrd, Munich, NYU, Toulouse, and the Banca d'Italia/CEPR Conference on Money Banking and Finance for helpful comments. The views expressed herein are those of the authors and not necessarily those of the National Bureau of Economic Research.

(C2003 by Romain Ranciere, Aaron Tornell and Frank Westermann. All rights reserved. Short sections of text, not to exceed two paragraphs, may be quoted without explicit permission provided that full credit, including (C) notice, is given to the source. 
Crises and Growth: A Re-Evaluation

Romain Ranciere, Aaron Tornell, and Frank Westermann

NBER Working Paper No. 10073

October 2003

JEL No. F34, F36, F43, O41

\section{$\underline{\text { ABSTRACT }}$}

We address the question of whether growth and welfare can be higher in crisis prone economies. First, we show that there is a robust empirical link between per-capita GDP growth and negative skewness of credit growth across countries with active financial markets. That is, countries that have experienced occasional crises have grown on average faster than countries with smooth credit conditions. We then present a two-sector endogenous growth model in which financial crises can occur, and analyze the relationship between financial fragility and growth. The underlying credit market imperfections generate borrowing constraints, bottlenecks and low growth. We show that under certain conditions endogenous real exchange rate risk arises and firms find it optimal to take on credit risk in the form of currency mismatch. Along such a risky path average growth is higher, but self-fulfilling crises occur occasionally. Furthermore, we establish conditions under which the adoption of credit risk is welfare improving and brings the allocation nearer to the Pareto optimal level. The design of the model is motivated by several features of recent crises: credit risk in the form of foreign currency denominated debt; costly crises that generate firesales and widespread bankruptcies; and asymmetric sectorial responses, where the nontradables sector falls more than the tradables sector in the wake of crises.

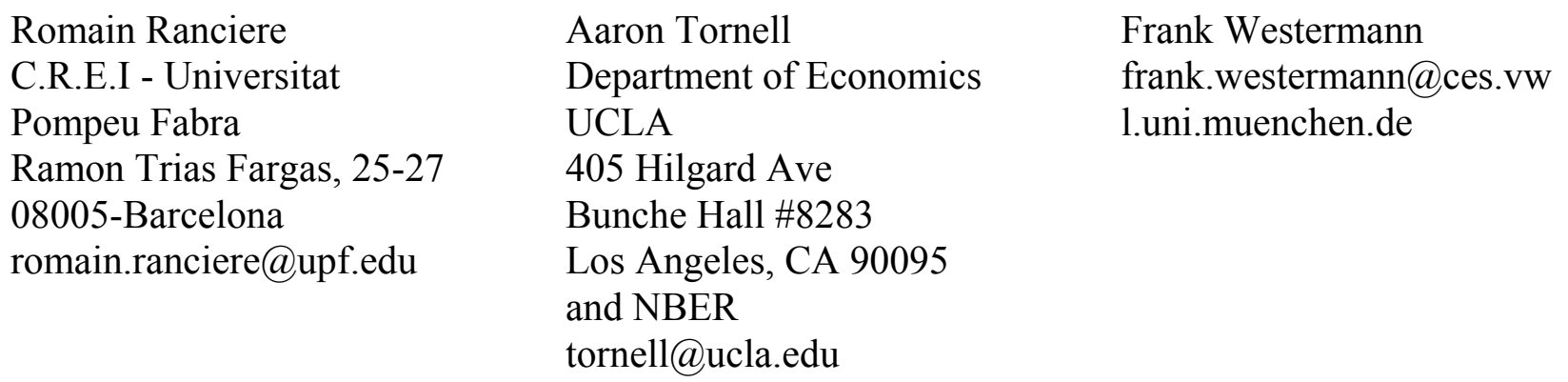




\section{Introduction}

Over the last two decades most of the fastest growing countries of the developing world have experienced lending booms and financial crises. Countries in which credit growth has been smooth have, by contrast, exhibited the lowest growth rates. It would thus appear that factors that contribute to financial fragility have also been a source of growth, even if they have led to occasional crises.

The link between financial fragility and long run growth is associated with two views of financial liberalization. In one view, financial liberalization induces excessive risk-taking, increases macroeconomic volatility and leads to more frequent crises. In another view, liberalization strengthens financial development and contributes to higher long-run growth.

In this paper we bring these two views together. First, we document a robust empirical link between higher growth and a propensity for crisis. Second, we present a model that establishes a link between crises models and growth models, and show that the two views of liberalization are complementary. We analyze the relationship between financial fragility and growth in an economy where credit market imperfections imply that a high growth path requires credit risk and the possibility of crisis. Furthermore, we carry out a welfare analysis and establish conditions under which the welfare costs of crises are outweighed by the benefits of higher growth.

The paper is in two parts. The first part is empirical and the second is a model. The empirical section establishes the link between higher GDP growth and negative skewness in credit growth across countries with active financial markets. This finding indicates that countries with stable credit market conditions have on average grown more slowly than countries that have experienced occasional crises, and have a credit growth rate distribution with a long left tail. ${ }^{1}$ But this does not imply that financial crises are good for growth. It suggests that undertaking credit risk has led to higher growth, but as a side-effect, it has also led to occasional crises.

In our empirical analysis, we find that the link between bumpiness and growth is not evident across countries with a high degree of contract enforceability (HECs), but only across

\footnotetext{
${ }^{1}$ Negative skewness indicates that good results are clustered closer to the mean than bad results. In other words, credit contractions are more abrupt and rare than credit expansions.
} 
those with moderate contract enforceability (MECs). In fact, over the past two decades most HECs have experienced skewness of credit growth that is near zero.

Thailand and India are contrasting examples of a steep but crisis prone growth path and a slow but safe growth path. Thailand has experienced lending booms and crises, while India has pursued a safe growth path for credit (see Figure 1). GDP per capita grew by only $99 \%$ between 1980 and 2001 in India, whereas Thailand's GDP per capita grew by 148\%, despite having experienced a major crisis. $^{2}$

The literature has shown that economic growth is negatively correlated with the variance of several macro aggregates. These findings do not conflict with our results: variance is just not a good instrument with which to capture the uneven progress associated with financial fragility. For instance, a country which experiences high frequency shocks will exhibit a high variance in credit growth even though it experiences neither the booms nor the busts of countries that are financially fragile.

The second part of the paper presents a model that links financial fragility and long-run growth, and derives the welfare implications of such a link. The model is designed to account also for prominent features of recent crisis episodes in MECs. Not only are crises marked by dramatic real depreciations, firesales and widespread bankruptcies, but they are characterized by a sharp sectorial asymmetry: output drops far more in the nontradables (N) sector than in the tradables $(\mathrm{T})$ sector. Closely related to this asymmetric sectorial response is the denomination of N-sector debt in foreign currency. In the model this currency mismatch is the source of financial fragility.

To explain the link between bumpiness and growth and at the same time account for the sectorial asymmetric response to crises, we consider a two-sector endogenous growth model with two credit market imperfections. First, there are contract enforceability problems that generate domestic financing constraints. These constraints affect primarily N-firms, as Tfirms have access to world capital markets. Second, there are bailout guarantees that insure lenders only against systemic crises. ${ }^{3}$

There is an equilibrium where crises never occur. Along this safe path the N-sector

\footnotetext{
${ }^{2}$ This fact is more remarkable given that in 1980 India's GDP was only about one fifth of Thailand's.

${ }^{3}$ We model these two imperfections as in Schneider and Tornell (2003). Their empirical relevance in MECs is analyzed in Tornell and Westermann (2003) .
} 
exhibits low growth because its investment is constrained by its cash flow. Since N-goods serve as intermediate inputs for both sectors, the N-sector constrains the long-run growth of the T-sector and that of GDP: there is a bottleneck.

However, under some circumstances there is also a risky equilibrium in which endogenous real exchange rate risk arises and firms find it optimal to take on credit risk in the form of currency mismatch. This risky behavior eases borrowing constraints, increases investment, alleviates the bottleneck and allows both sectors to grow faster. However, it also generates financial fragility, as a shift in expectations can cause a sharp real depreciation and land the economy in a crisis.

Crises are costly. Real depreciation leads to firesales and bankrupts N-sector firms with foreign currency debt on their books. Furthermore, the resultant collapse in cash flow depresses new credit and investment, hampering growth. We ask the question: does the credit risk that leads to financial fragility increase long run GDP growth by compensating for the effects of contract enforceability problems? Our first theoretical result is that a financially fragile economy will, on average, grow faster than a safe economy even if crisis costs are large, provided that contract enforceability problems are severe, but not too severe. This result follows, in part, from the fact that crises must be rare events in order for credit risk to be profitable for individual borrowers. Since crises must be rare events in order for them to occur in equilibrium and during a crisis credit falls abruptly but recuperates gradually, in the model negative skewness of credit growth is associated with higher long-run growth.

Having a microfounded model allows us to examine the relationship between financial fragility, production efficiency and social welfare. Because both sectors compete every period for the available supply of N-goods, when contract enforceability problems are very severe, the N-sector attains low leverage and commands only a small share of N-inputs. This results in a socially inefficient low growth path: a central planner would increase the N-sector investment share to attain the Pareto optimal allocation.

Clearly, the first best can be attained in a decentralized economy by reducing the agency problems that generate the financing constraints. However, if such a reform is not feasible, credit risk may be a second best instrument to increase social welfare despite financial fragility. Our second theoretical result is that when contract enforceability problems are se- 
vere, but not too severe, and crisis costs are not too large, credit risk increases social welfare and brings the allocation nearer to the Pareto optimal level.

The existence of the risky equilibrium depends on systemic bailout guarantees. Since these guarantees are funded by domestic taxation the question arises as to whether such a policy can be implemented. We show that if $\mathrm{N}$-inputs are intensively used in T-production, the T-sector will find it profitable to fund the fiscal cost of the guarantees. The funding of the guarantees actually effects a redistribution from the non-constrained T-sector to the constrained N-sector. This redistribution is to the mutual benefit of both sectors because T-production enjoys cheaper and more abundant N-inputs, and its growth rate increases: the bottleneck is eased. Thus, even those who bear the costs of crises may be willing to pay their price.

We wish to make a few comments on how our model relates to the literature. ${ }^{4}$ First, the credit cycles in this paper are different from Schumpeterian cycles in which the adoption of new technologies plays a key role. Rather our cycles resemble Juglar credit cycles. Second, although our model contains some elements of third generation crisis models, it is primarily a two-sector long-run growth model where crises can occur. This allows for explicit welfare analysis.

Finally, our empirical finding that bumpiness is associated with higher long-run growth offers an explanation for the positive link between financial liberalization and growth found by some researchers, and the positive impact of financial liberalization on the frequency of crises find by others. Our model can help explain why, by allowing agents to take on more credit risk and easing borrowing constraints, financial liberalization may lead to both higher growth and a greater incidence of crises.

Section 2 contains our empirical findings. Section 3 presents the model. Section 4 derives the limit distributions of output and credit growth, and links the model to our empirical findings. Section 5 analyzes production efficiency and welfare. Section 6 relates our paper to the literature. Section 7 concludes.

\footnotetext{
${ }^{4}$ See Section 6 for a detailed review of the literature.
} 


\section{Bumpiness and Growth: The Empirical Link}

Here, we investigate whether countries with risky credit paths that have experienced financial crises have grown faster, on average, than other countries. We will measure the incidence of financial crises with the negative skewness of real credit growth. ${ }^{5}$ Along a boom-bust episode there is high credit growth during the lending boom, a sharp and abrupt downward jump during the crisis, and slow credit growth during the credit crunch that develops in the wake of the crisis. Since credit does not experience sharp jumps during the boom and crises happen only occasionally, the distribution of credit growth rates is characterized by negative outliers. ${ }^{6}$ Therefore, countries that experience a boom-bust episode exhibit a negatively skewed distribution of credit growth. For this reason we will refer to negative skewness as bumpiness. $^{7}$

Boom-bust episodes are associated not only with negative skewness, but also with high variance of credit growth -the typical measure of volatility in the literature. We choose not to use the variance to identify risky credit paths that lead to infrequent crises because high variance may also reflect high frequency shocks, which might be exogenous or might be self-inflicted by, for instance, bad economic policy. Since high frequency shocks are more abundant in the sample we consider than the rare crises that punctuate lending booms, variance is not a good means of distinguishing risky from safe paths.

In principle, we could also identify countries that have followed risky paths by looking

\footnotetext{
${ }^{5}$ Skewness is a measure of asymmetry of the distribution of the series around its mean and is computed as $S=\frac{1}{n} \sum_{i=1}^{n} \frac{\left(y_{i}-\bar{y}\right)^{3}}{\widehat{\sigma}}$, where $\bar{y}$ is the mean and $\hat{\sigma}$ is the standard deviation. The skewness of a symmetric distribution, such as the normal distribution, is zero. Positive skewness means that the distribution has a long right tail and negative skewness implies that the distribution has a long left tail.

${ }^{6}$ During a lending boom there are positive growth rates that are above normal. However, they are not positive outliers because the lending boom takes place for several years. Only a positive one-period jump in credit would create a positive outlier in growth rates. For instance, Thailand experienced a lending boom for almost all of the sample period and most of the distribtuion is centered around a very high mean.

${ }^{7}$ Crises are rare events and in a short sample period not all risky lending booms need to end in a bust (see Gourinchas et. al (2001) and Tornell and Westermann (2002)). Countries that experience risky lending booms without having a crisis do not exhibit a negatively skewed distribution of credit growth. Notice, however, that during our sample period (1980-1999) most countries that have followed risky credit paths have experienced at least one major crisis.
} 
Figure 1: Safe vs. Risky Growth Paths

Credit:

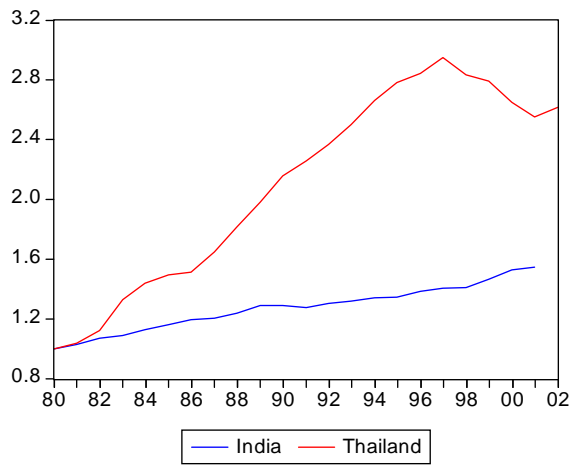

GDP per capita:

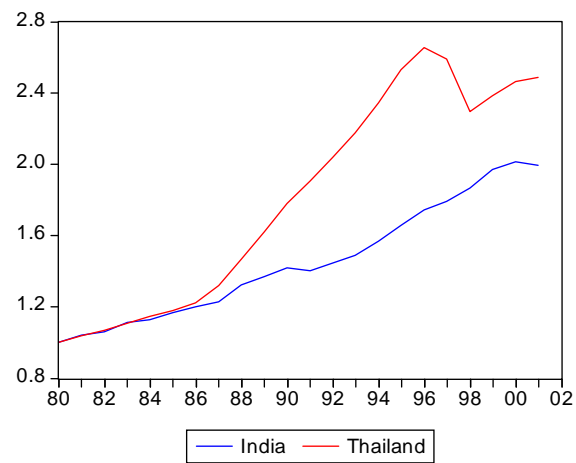

Note: The values for 1980 are normalized to one.

at the skewness of GDP growth. In practice, however, this may be unreliable because the tradables sector is typically not negatively affected during crises. Since this sector has access to world capital markets, tradables production does not decline as much as nontradables production during crises and often goes up (due to the real depreciation in the exchange rate). As a result, the decline in GDP is much milder than the decline in credit. ${ }^{8}$

The kernel distributions of credit growth rates for India and Thailand are given in Figure $2 .^{9}$ India, the safe country, has a low mean and is quite tightly distributed around the mean -with skewness close to zero. Meanwhile, Thailand, the risky country, has a very asymmetric

\footnotetext{
${ }^{8}$ Furthermore, our model indicates that skewness of GDP is not as good a test of a risky path as skewness of credit growth. Because the T-sector has access to international capital markets and benefits from the real depreciation, the model predicts that a crisis will affect GDP much less than it affects the bank-dependent $\mathrm{N}$-sector and credit growth.

${ }^{9}$ The simplest nonparametric density estimate of a distribution of a series is the histogram. The histogram, however, is sensitive to the choice of origin and is not continuous. We therefore choose the more illustrative kernel density estimator, which smoothes the bumps in the histogram (see Silverman 1986). Smoothing is done by putting less weight on observations that are further from the point being evaluated. The Kernel function by Epanechnikov is given by: $\frac{3}{4}\left(1-(\Delta B)^{2}\right) I(|\Delta B| \leq 1)$, where $\Delta B$ is the growth rate of real credit and $I$ is the indicator function that takes the value of one if $|\Delta B| \leq 1$ and zero otherwise. The bandwidth, $h$, controls for the smoothness of the of the density estimate. The larger is $\mathrm{h}$, the smoother the estimate. For comparability, we choose the same $h$ for both graphs.
} 
distribution and is characterized by a much larger negative skewness.

Figure 2: Distributions and Kernel Densities of Real Credit Growth
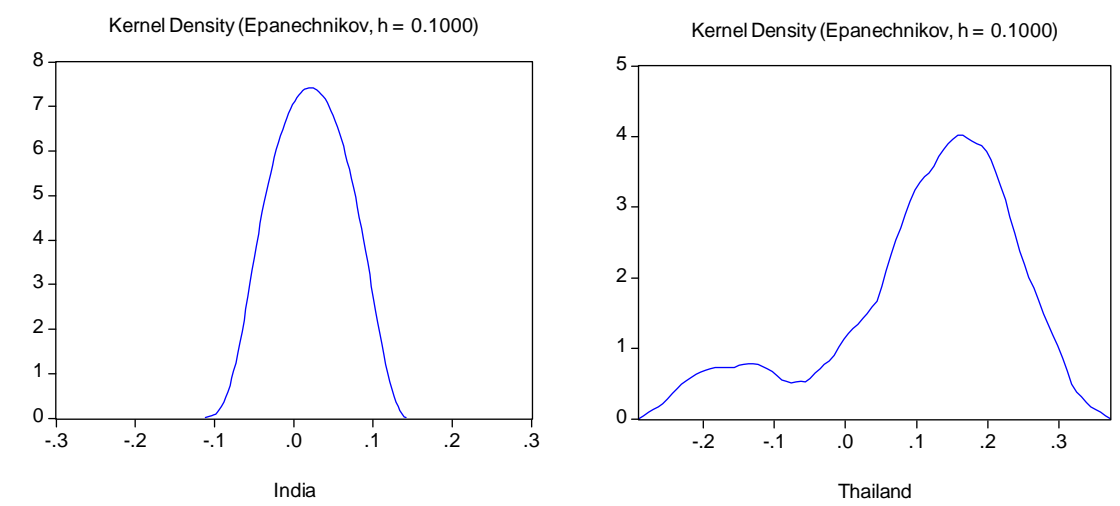

\begin{tabular}{lcc}
\hline \hline & India & Thailand \\
\cline { 2 - 3 } Mean & 0.021 & 0.109 \\
Std. Dev. & 0.014 & 0.125 \\
Skewness & -0.370 & -1.108 \\
\hline \hline
\end{tabular}

To establish that the positive relationship between GDP growth and negative skewness of real credit growth is not specific to India and Thailand, we use cross-country regressions. Because our model indicates that countries with extreme contract enforceability problems will not be able to generate credit risk, we restrict our data to those countries with functioning financial markets. Our criterion for inclusion in the set is that a country have a stock market turnover-to-GDP ratio of at least 1\% in 1998. ${ }^{10}$ This set contains 66 countries, 52 of which have data available during the 1980s and 1990s. ${ }^{11}$

To assess the link between bumpiness and growth we add the three moments of real credit growth to a standard growth regression:

$$
\Delta y_{i t}=\lambda y_{i 0}+\gamma^{\prime} X_{i t}+\beta_{1} \mu_{\Delta B, i t}+\beta_{2} \sigma_{\Delta B, i t}+\beta_{3} S_{\Delta B, i t}+\varepsilon_{i t},
$$

where $\Delta y_{i t}$ is the average growth rate of per-capita GDP; $y_{i 0}$ is the initial level of per capita GDP; $\mu_{\Delta B, i t}, \sigma_{\Delta B, i t}$ and $S_{\Delta B, i t}$ are the mean, standard deviation and skewness of the real

\footnotetext{
${ }^{10}$ We have chosen 1998 because it is the year with maximum data availability.

${ }^{11}$ In order to compute the higher moments, we consider only series for which we have at least ten years of data. Our source of data is World Development Indicators (WDI) of the World Bank.
} 
credit growth rate, respectively. $X_{i t}$ is a vector of control variables that includes initial human capital, average population growth rate, and life expectancy. We do not include investment in (1) as we expect the three moments of credit growth, our variables of interest, to affect GDP growth through higher investment. ${ }^{12}$

We estimate the regression in three different ways. First, we estimate a standard crosssection regression by OLS. In this case 1980 is the initial year and the moments of credit growth are computed over the entire sample period 1980-1999. Second, we estimate a panel regression using two non-overlapping windows: 1980-1989 and 1990-1999. In this case we use two sets of credit growth moments, one for each window. Lastly, we use overlapping averages. We construct 10-year averages starting with the period 1980-1989 and rolling it forward to the period 1990-1999, for each country and each variable. Thus, each country has up to 10 data points in the time series dimension. ${ }^{13}$ We estimate the panel regressions using generalized least squares. We deal with the resulting autocorrelation in the residuals by adjusting the standard errors according to Newey and West (1987). ${ }^{14}$

Table 1 reports the estimation results for the three regressions. We find that, after controlling for the standard variables, the mean growth rate of credit has a positive effect on long-run GDP growth. This has already been established in the literature. What we establish is the bumpiness of credit that accompanies high growth across the set of countries with functioning financial markets. The first three columns show that negative skewness $-\mathrm{a}$ bumpier growth path- is on average associated with higher GDP growth. These estimates are significant at the $5 \%$ level in the panel regressions and the $10 \%$ level in the cross-section.

The model shows that the link between growth and bumpiness exists only across economies with significant contract enforceability problems (that are not too extreme). In the absence of such problems, the borrowing constraints that drive our results do not arise in equilibrium. To capture this distinction, we divide our sample into countries with either high or middle enforceability of contracts (HECs and MECs). We classify as HECs the G7 countries and

\footnotetext{
${ }^{12}$ The selection of control variables follows the selection in the previous studies most closely related to ours: Bekaert, et.al. (2001), and Levine and Renelt (1991).

${ }^{13}$ Bekaert et.al. (2001) also consider overlapping averages. They look at shorter averages, but this is not feasible in our case, as the higher moments of credit growth cannot be computed in a meaningful way.

${ }^{14}$ Our panel is unbalanced because not all series are available for all countries and for all periods.
} 
those with a Kraay and Kaufman's rule of law index of no less than 1.4. This classification generates 35 MECs and 17 HECs. ${ }^{15}$

The fourth column in Table 1 reports the estimation results for a regression equation that adds to (1) the following three terms: $\beta_{4} * h e c * \mu_{\Delta B, i t}+\beta_{5} * h e c * \sigma_{\Delta B, i t}+\beta_{6} * h e c * S_{\Delta B, i t}$, where hec is a dummy variable that equals one for HECs and zero otherwise. ${ }^{16}$ This column shows that across MECs there is a strong link between bumpiness and growth. In contrast, this link is not evident across HECs. The point estimate of the bumpiness coefficient for MECs is $\beta_{3}=0.25$, and it is significant at the $5 \%$ level. Meanwhile, that for HECs is only $\beta_{3}+\beta_{6}=0.18$, and Wald tests reveal that although the mean and the variance of credit growth have a significant effect on GDP growth (at the $5 \%$ level), skewness does not. In fact, HECs have experienced near zero skewness in credit growth during the last two decades.

To interpret the estimate of 0.265 for bumpiness, consider India, with near zero skewness, and Thailand with skewness of minus two. A point estimate of 0.265 implies that an increase in the bumpiness index of two (from 0 to -2 ), increases the average long run GDP growth rate by $0.53 \%$ per year. Is this estimate economically meaningful? To address this question note that after controlling for the standard variables Thailand grows about $2 \%$ more per year than India. Thus, about a quarter of this growth differential can be attributed to credit risk taking, as measured by the skewness of credit growth.

Next, consider the variance of credit growth. Consistent with the literature, the variance enters with a negative sign and it is significant at the $5 \%$ level in all regressions. ${ }^{17}$ We can interpret the negative coefficient on variance as capturing the effect of 'bad volatility' generated by, for instance, procyclical fiscal policy. Meanwhile, the positive coefficient on

\footnotetext{
${ }^{15}$ The HECs are: Australia, Austria, Canada, Denmark, Finland, France, Germany, Italy, Japan, Luxembourg, Netherlands, New Zealand, Norway, Sweden, Switzerland, UK, and United States. The MECs are: Argentina, Bangladesh, Belgium, Brazil, Chile, China, Colombia, Ecuador, Egypt, Greece, Hong Kong, Hungary, India, Indonesia, Ireland, Israel, Jordan, Korea, Malaysia, Mexico, Morocco, Pakistan, Peru, Philippines, Poland, Portugal, South Africa, Spain, Sri Lanka, Thailand, Tunisia, Turkey, Uruguay, Venezuela and Zimbabwe.

${ }^{16}$ The effects of the moments of credit growth on GDP growth are captured by $\left(\beta_{1}, \beta_{2}, \beta_{3}\right)$ in MECs, and by $\left(\beta_{1}+\beta_{4}, \beta_{2}+\beta_{5}, \beta_{3}+\beta_{6}\right)$ in HECs.

${ }^{17}$ Ramey and Ramey (1995), and Fatas and Mihov (2002) find that fiscal policy induced volatility is bad for economic growth.
} 
Table 1: Bumpiness and Growth

Dependent variable: Real per capita GDP growth

\begin{tabular}{|c|c|c|c|c|}
\hline & (1) & (2) & (3) & (4) \\
\hline & Cross section & $\begin{array}{c}\text { Panel (non- } \\
\text { overlapping) }\end{array}$ & $\begin{array}{c}\text { Panel } \\
\text { (overlapping) }\end{array}$ & $\begin{array}{l}\text { HEC vs. MEC } \\
\text { (overlapping) }\end{array}$ \\
\hline Initial per capita GDP & $\begin{array}{c}-0.914 * * \\
(0.320)\end{array}$ & $\begin{array}{c}-1.165^{* * *} \\
(0.242)\end{array}$ & $\begin{array}{c}-1.269 * * \\
(0.060)\end{array}$ & $\begin{array}{c}-1.061 * * \\
(0.068)\end{array}$ \\
\hline Secondary schooling & $\begin{array}{l}-0.002 \\
(0.014)\end{array}$ & $\begin{array}{c}0.009 \\
(0.014)\end{array}$ & $\begin{array}{c}0.005 \\
(0.003)\end{array}$ & $\begin{array}{c}0.006 \\
(0.004)\end{array}$ \\
\hline Population growth & $\begin{array}{c}-0.010 * * \\
(0.002)\end{array}$ & $\begin{array}{c}-0.009 * * \\
(0.002)\end{array}$ & $\begin{array}{c}-0.010 * * \\
(0.001)\end{array}$ & $\begin{array}{c}-0.009 * * \\
(0.001)\end{array}$ \\
\hline Life expectancy & $\begin{array}{c}0.072 * * \\
(0.015)\end{array}$ & $\begin{array}{l}0.165 * * \\
(0.029)\end{array}$ & $\begin{array}{c}0.166^{* * *} \\
(0.016)\end{array}$ & $\begin{array}{c}0.169 * * \\
(0.016)\end{array}$ \\
\hline Credit_mean & $\begin{array}{l}0.091^{*} \\
(0.048)\end{array}$ & $\begin{array}{l}0.151 * * \\
(0.034)\end{array}$ & $\begin{array}{l}0.154 * * \\
(0.011)\end{array}$ & $\begin{array}{l}0.184 * * \\
(0.014)\end{array}$ \\
\hline Credit_Variance & $\begin{array}{c}-0.044 * * \\
(0.017)\end{array}$ & $\begin{array}{c}-0.036 * * \\
(0.017)\end{array}$ & $\begin{array}{c}-0.030 * * \\
(0.004)\end{array}$ & $\begin{array}{c}-0.041 * * \\
(0.006)\end{array}$ \\
\hline -(Credit_Skewness) & $\begin{array}{l}0.211^{*} \\
(0.119)\end{array}$ & $\begin{array}{c}0.302 * * \\
(0.148)\end{array}$ & $\begin{array}{c}0.265^{* *} * \\
(0.040)\end{array}$ & $\begin{array}{c}0.250 * * \\
(0.093)\end{array}$ \\
\hline Credit_mean*HEC & & & & $\begin{array}{c}-0.142 * * \\
(0.023)\end{array}$ \\
\hline Credit_Variance*HEC & & & & $\begin{array}{l}-0.009 \\
(0.009)\end{array}$ \\
\hline -(Credit_Skewness)*HEC & & & & $\begin{array}{l}-0.072 \\
(0.113)\end{array}$ \\
\hline \# of observations & 51 & 84 & 424 & 424 \\
\hline
\end{tabular}

Note: The table shows the results of the regression.:

$\Delta \mathrm{y}_{\mathrm{it}}=\lambda \mathrm{y}_{\mathrm{i}, \text { ini }}+\gamma \mathrm{X}_{\mathrm{it}}+\beta_{1} \mu_{\Delta B, i t}+\beta_{2} \sigma_{\Delta B, i t}+\beta_{3} S_{\Delta B, i t}+\varepsilon_{i t}$, where $\Delta y_{i t}$ is the average growth rate of percapita GDP; $\mathrm{y}_{\mathrm{i}, \text { ini }}$ is the initial level of per-capita GDP; and $\mu_{\Delta B, i t}, \sigma_{\Delta B, i t}$ and $S_{\Delta B, i t}$ are the mean, standard deviation and skewness of the real credit growth rate, respectively. $\mathrm{X}_{\mathrm{it}}$ is a vector of control variables that includes initial human capital, the average population growth rate, and life expectancy. Column (1) shows the results for a standard cross section regression, estimated by OLS for the sample period 1980 to 1999. Column (2) shows the results for a non-overlapping panel regression with two periods, one from 1980-1989 and one from 1990 to 1999. Column (3) reports the results from an overlapping panel regression. For each country and each variable, we construct 10-year averages starting with the period 1980-1989 and rolling it forward to the period 1990-1999. Column (4) separates the sample in HEC and MEC countries. The panel regression is estimated using a GLS estimator. Heteroscedasticity consistent standard errors are computed using the Newey and West procedure and are reported in parentheses; * indicates significance at the 10 percent level and ** indicates significance at the 5 percent level.

Wald Tests

H0: Sum of HEC and MEC coefficient $=0$

\begin{tabular}{lcc} 
& F-statistic & (p-value) \\
Credit-mean & 5.029 & 0.025 \\
Credit-variance & 4.430 & 0.038 \\
Credit skewness & 0.005 & 0.942 \\
\hline
\end{tabular}


bumpiness captures the 'good volatility' associated with the type of risk taking that eases financial constraints and increases investment. ${ }^{18}$ Notice that a country with high variance need not have negative skewness.

Figure 3 shows graphically the link between GDP growth and the moments of credit growth across MECs. It is evident that higher long run GDP growth is associated with (a) a higher mean growth rate in credit, (b) lower variance and (c) negative skewness. In other words, high GDP growth rates are associated with a risky and bumpy credit path. Consider specific examples: Chile, Thailand and Korea, exhibit negatively skewed credit growth and high GDP growth. In contrast, countries that do not exhibit negative skewness, like Pakistan, Bangladesh and Morocco have low growth. China and Ireland are notable outliers: they have experienced very high GDP growth in the last twenty years, but have not experienced a crisis.

In sum, our findings show that MECs that followed a risky credit path and have experienced boom-bust episodes have on average grown faster than MECs with stable credit conditions. These results do not imply that crises are good for growth. They say that undertaking credit risk has led to higher growth, but as a side-effect, it has also led to occasional crises.

\section{Model}

We consider an infinite horizon endogenous growth model of a two-sector small open economy with credit market imperfections. There are two goods: a tradable ( $\mathrm{T}$ ) good, which is a consumption good, and a nontradable $(\mathrm{N})$ good, which is used as an input in the production of both goods. We will denote the relative price of N-goods (i.e., the inverse of the real exchange rate) by $p_{t}=p_{t}^{N} / p_{t}^{T}$. The only source of uncertainty is endogenous real exchange rate risk: in equilibrium $p_{t+1}$ may equal $\bar{p}_{t+1}$ with probability $u_{t+1}$ or $\underline{p}_{t+1}$ with probability $1-u_{t+1}$. The probability $u_{t+1}$ may equal either 1 or $u$, and this is known at $t$.

There are competitive risk neutral international investors whose cost of funds equals the world interest rate $r$. These investors lend any amount as long as they are promised an

\footnotetext{
${ }^{18}$ This view is consistent with the findings of Imbs (2002).
} 
Figure 3: Moments of Credit and GDP Growth

a) Growth and Mean

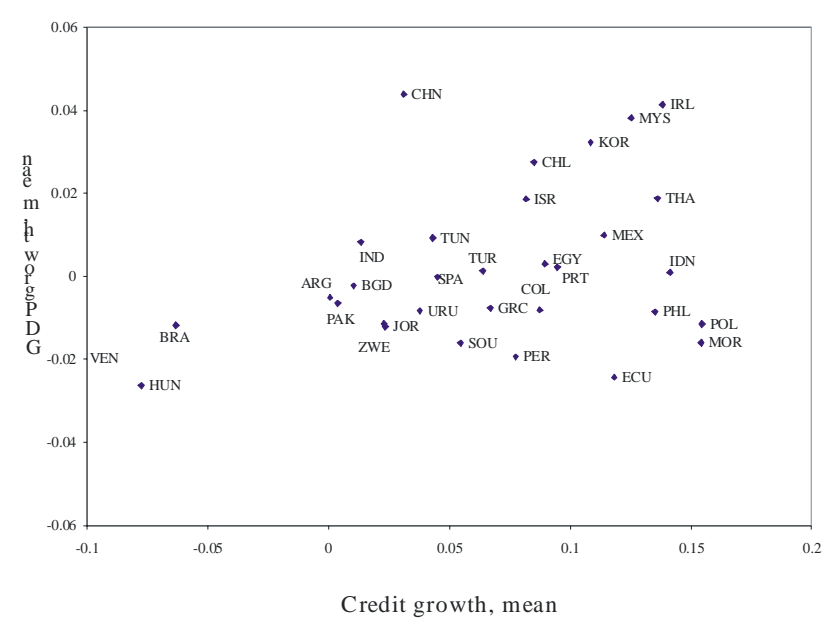

\section{b) Growth and Variance}

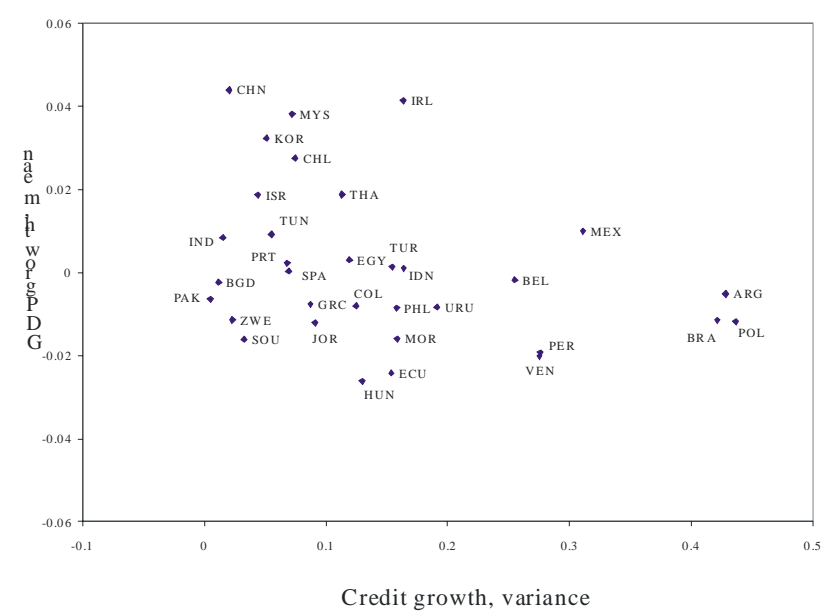

c) Growth and Skewness

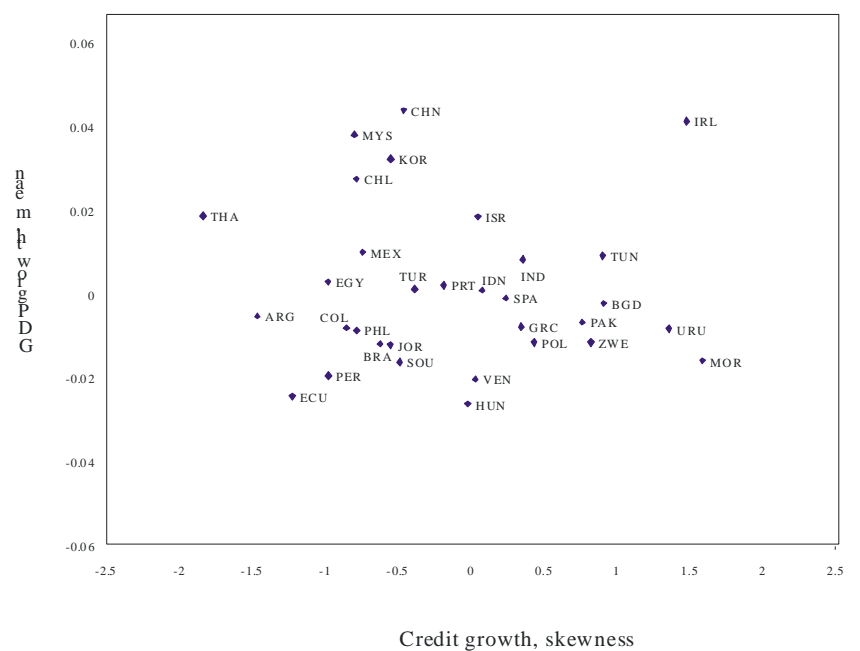

Note: The graphs plot the moments of real credit growth from 1988-1999 against the residuals of a growth regression that controls for initial per capita GDP and population growth. 
expected payoff of $1+r$. They also issue default-free bonds: an N-bond and a T-bond. The T-bond pays $1+r$ next period, while the N-bond pays $\left(1+r_{t}^{n}\right) p_{t+1}$. The existence of risk neutral deep-pocket investors implies that uncovered interest parity will hold in any equilibrium

$$
\left(1+r_{t}^{n}\right) p_{t+1}^{e}=1+r, \quad \text { where } p_{t+1}^{e}:=u_{t+1} \bar{p}_{t+1}+\left(1-u_{t+1}\right) \underline{p}_{t+1}
$$

There is a continuum, of measure one, of competitive firms that produce the T-good using a nontradable input $\left(d_{t}\right)$ and a non-reproducible factor $\left(l_{t}^{T}\right)$. The representative Tfirm maximizes profits taking as given the price of N-goods $\left(p_{t}\right)$ and the price of the nonreproducible factor $\left(v_{t}^{T}\right)$ :

$$
\max _{\left\{d_{t+j}, l_{t+j}^{T}\right\}_{j=0}^{\infty}}\left[y_{t+j}-p_{t+j} d_{t+j}-v_{t+j}^{T} l_{t+j}^{T}\right], \quad y_{t+j}=a_{t+j} d_{t+j}^{\alpha}\left(l_{t+j}^{T}\right)^{1-\alpha}, \quad \alpha \in(0,1)
$$

There is a continuum, of measure one, of consumers. The representative consumer is infinitely lived, consumes only T-goods, and is endowed with one unit of the non-reproducible factor, which he supplies inelastically $\left(l_{t}^{T}=1\right)$. Furthermore, he can buy and sell any amount of the two default-free bonds described above. Since capital markets are complete, he solves the following problem

$$
\max _{\left\{c_{t+j}\right\}_{j=0}^{\infty}} E_{t} \sum_{j=0}^{\infty} \delta^{j} U\left(c_{t+j}\right), \quad \text { st. } E_{t} \sum_{j=0}^{\infty} \delta^{j}\left[c_{t+j}-v_{t+j}^{T}+T_{t+j}\right] \leq 0, \quad \delta:=\frac{1}{1+r}
$$

where $T_{t}$ is the tax that will finance the bailouts.

There is a continuum, of measure one, of firms that produce N-goods using entrepreneurial labor $\left(l_{t}\right)$, and capital $\left(k_{t}\right)$. Capital consists of $\mathrm{N}$-goods invested during the previous period $\left(I_{t-1}\right)$, which fully depreciates after one period. The production function is

$$
q_{t}=\Theta_{t} k_{t}^{\beta} l_{t}^{1-\beta}, \quad \Theta_{t}=: \theta{\overline{k_{t}}}^{1-\beta}, \quad k_{t}=I_{t-1}, \quad \beta \in(0,1)
$$

The technological parameter $\Theta_{t}$ embodies an external effect, where $\overline{k_{t}}$ is the average $\mathrm{N}$-sector capital, that each firm takes as given.

The investable funds of an N-firm consist of its cash flow $w_{t}$ plus the debt it issues. In order to capture the debt denomination decision we assume that the firm can issue T-debt $\left(b_{t}\right)$ and $\mathrm{N}$-debt $\left(b_{t}^{n}\right)$ that promise to repay next period $L_{t+1}=\left(1+\rho_{t+1}\right) b_{t}$ and $p_{t+1} L_{t+1}^{n}=$ 
$p_{t+1}\left(1+\rho_{t+1}^{n}\right) b_{t}^{n}$, respectively. Funds can be used to buy default-free bonds $\left(s_{t}, s_{t}^{n}\right)$ or N-goods $\left(p_{t} I_{t}\right)$ in order to produce N-goods in the following period. Since $b_{t}$ and $b_{t}^{n}$ are measured in T-goods, the time $t$ budget constraint and time $t+1$ profits are, respectively

$$
\begin{gathered}
p_{t} I_{t}+s_{t}+s_{t}^{n}=w_{t}+b_{t}+b_{t}^{n} \\
\pi\left(p_{t+1}\right)=p_{t+1} q_{t+1}+(1+r) s_{t}+p_{t+1}\left(1+r_{t}^{n}\right) s_{t}^{n}-v_{t+1} l_{t+1}-L_{t+1}-p_{t+1} L_{t+1}^{n}
\end{gathered}
$$

Firms are run by overlapping generations of entrepreneurs who live for two periods and consume only tradables in the second period of their life. At the beginning of time $t$ a young entrepreneur supplies inelastically one unit of labor $\left(l_{t}=1\right)$ and receives a wage $v_{t}$. At the end of time $t$ she takes control of the firm and makes investment and financing decisions. The cash flow of the firm equals the entrepreneur's wage: $w_{t}=v_{t}$.

$\mathrm{N}$-sector financing is subject to two credit market imperfections: contract enforceability problems and systemic bailout guarantees that cover lenders against systemic crises. The former will give rise to borrowing constraints in equilibrium, while the latter will induce firms to undertake insolvency risk through currency mismatch. We model these imperfections using the credit market game of Schneider and Tornell (2003), henceforth ST.

Contract Enforceability Problems. Entrepreneurs cannot commit to repay debt: if at time $t$ the entrepreneur incurs a non-pecuniary cost $h\left[w_{t}+b_{t}+b_{t}^{n}\right]$, then at $t+1$ she will be able to divert all the returns provided the firm is solvent.

Systemic Bailout Guarantees. There is a bailout agency that pays lenders the outstanding debts of all defaulting firms if more than $50 \%$ of firms become insolvent (i.e., $\pi\left(p_{t-1}\right)<0$ ). The guarantee applies to both $\mathrm{N}$ - and T-debt. The bailout agency recuperates a share $\mu$ of the insolvent firms' revenues. The remainder is financed by lump-sum taxes on consumers.

The goal of every entrepreneur is to maximize next period's expected profits net of diversion costs. Since guarantees are systemic, the decisions of entrepreneurs are interdependent. Therefore, their decisions will be determined in the following credit market game considered by ST. During each period $t$, taking prices as given, every young entrepreneur proposes a plan $P_{t}=\left(I_{t}, s_{t}, s_{t}^{n}, b_{t}, b_{t}^{n}, \rho_{t}, \rho_{t}^{n}\right)$ that satisfies budget constraint (6). Lenders then decide whether to fund these plans. Finally, funded young entrepreneurs make investment and diversion decisions. 
Payoffs are determined at $t+1$. Consider first plans that do not lead to diversion. If the firm is solvent $\left(\pi\left(p_{t+1}\right) \geq 0\right)$, the old entrepreneur pays $v_{t+1}$ to the young entrepreneur and $L_{t+1}+p_{t+1} L_{t+1}^{n}$ to lenders. She then consumes the profit $c_{t+1}^{e}=\pi\left(p_{t+1}\right)$. In contrast, if the firm is insolvent $\left(\pi\left(p_{t+1}\right)<0\right)$, young entrepreneurs receive $\mu_{w} p_{t+1} q_{t+1}\left(\mu_{w}<1-\beta\right)$, lenders receive the bailout if any is granted, and old entrepreneurs get nothing. If a diversion scheme is in place and the firm is solvent, the old entrepreneur gets $\beta p_{t+1} q_{t+1}$ and nothing otherwise; young entrepreneurs get $[1-\beta] p_{t+1} q_{t+1}$ and lenders receive the bailout if any is granted. The problem of a young entrepreneur is then to choose an investment plan $P_{t}$ and diversion strategy $\eta_{t}$ to solve:

$$
\begin{array}{cc}
\max _{P_{t}, \eta_{t}} & E_{t}\left(\xi _ { t + 1 } \left\{p_{t+1} q_{t+1}+(1+r) s_{t}+p_{t+1}\left(1+r^{n}\right) s_{t}^{n}-v_{t+1} l_{t+1}\right.\right. \\
& \left.\left.-\left[1-\eta_{t}\right]\left[L_{t+1}+p_{t+1} L_{t+1}^{n}\right]-h \eta_{t}\left[w_{t}+b_{t}+b_{t}^{n}\right]\right\}\right) \quad \text { s.t. (6), }
\end{array}
$$

where $\eta_{t}=1$ if the entrepreneur has set up a diversion scheme, and zero otherwise; and $\xi_{t+1}=1$ if $\pi\left(p_{t+1}\right) \geq 0$, and zero otherwise. The following definition integrates the credit market game with the rest of the economy.

Definition. A symmetric equilibrium is a collection of stochastic processes

$\left\{I_{t}, s_{t}, s_{t}^{n}, b_{t}, b_{t}^{n}, \rho_{t}, \rho_{t}^{n}, d_{t}, c_{t}, y_{t}, q_{t}, u_{t}, p_{t}, w_{t}, v_{t}, v_{t}^{T}\right\}$ such that, (i) given current prices and the distribution of future prices the plan $\left(I_{t}, s_{t}, s_{t}^{n}, b_{t}, b_{t}^{n}, \rho_{t}, \rho_{t}^{n}\right)$ is determined in a symmetric subgame perfect equilibrium of the credit market game, $d_{t}$ maximizes $T$-firms profits and $c_{t}$ maximizes consumers expected utility; (ii) factor markets clear; and (iii) the market for non-tradables clears: $d_{t}+I_{t}=q_{t}$.

To close the model we assume that date zero young entrepreneurs are endowed with $w_{0}=(1-\beta) p_{o} q_{o}$ units of T-goods, while old entrepreneurs are endowed with $q_{o}$ units of $\mathrm{N}$-goods and have no debt in the books. Finally, we impose the condition that guarantees are domestically financed through taxation:

$$
E_{t} \sum_{j=0}^{\infty} \delta^{j}\left[1-\xi_{t+j}\right]\left[L_{t+j}+p_{t+j} L_{t+j}^{n}-\mu p_{t+j} q_{t+j}-T_{t+j}\right]=0, \quad \mu \in[0, \beta] .
$$

\subsection{Discussion of the Setup}

To investigate how the forces that generate higher growth also generate financial fragility we consider a setup with no exogenous shocks. In equilibrium fragility will arise from a self- 
reinforcing mechanism: N-firms find it profitable to issue T-debt in the presence of systemic guarantees and sufficient real exchange rate variability. This variability, in turn, may arise because there is enough T-debt issued by N-firms. Clearly, there are other self-reinforcing mechanisms that generate endogenous financial fragility. The concrete mechanism we model here, however, captures some features of recent boom-bust episodes.

In our setup there are complete markets. Since during each period the real exchange rate can take only two values, the menu of securities allows consumers and firms to hedge all risk. ${ }^{19}$ This will allow us to make the point that growth and welfare gains arise from the undertaking of credit risk, not from consumption smoothing.

The assumption that N-goods are used as inputs is key. The use of N-inputs in Nproduction is necessary for the existence of endogenous real exchange rate variability. Otherwise, self-fulling crises could not occur. The use of N-inputs in T-production together with external effects in N-production imply that the N-sector is the source of endogenous growth in the economy. This, in turn, underlies the result that the undertaking of credit risk by increasing N-production may increase social welfare, and that the T-sector may derive a net benefit from financing the fiscal costs of the guarantees. In contrast, the assumptions that $\mathrm{N}$-goods are not consumed and T-goods are not intermediate inputs are convenient but not essential. $^{20}$

To capture the dynamic and the static effects of crises we have allowed for two types of crisis costs: financial distress $\left((1-\beta) / \mu_{w}\right)$ and bankruptcy costs $(\beta / \mu)$. All the equilibria we characterize exist for any $\mu_{w} \in(0,1-\beta)$ and $\mu \in[0, \beta]$.

Financing opportunities are asymmetric across sectors because only N-sector credit is affected by contract enforceability problems. This assumption captures the fact that most of the firms in MECs that can access international financial markets are in the T-sector. In contrast, most N-sector firms are dependent on domestic bank credit. ${ }^{21}$

The agency problem and the two-period lived entrepreneur set-up is taken from ST. The

\footnotetext{
${ }^{19}$ In particular, N-debt is a perfect hedge for N-sector firms.

${ }^{20}$ If $\mathrm{N}$-goods were consumed, there would a deeper fall in the demand of N-goods when N-firms become insolvent, accentuating the self-fulfilling depreciation that generates crisis.

${ }^{21}$ This is in part because T-firms can either pledge export receivables as collateral, or can get guarantees from closely linked firms. Tornell and Westermann (2003) document sectorial asymmetries as well as systemic guarantees in MECs.
} 
advantage of this set-up is that one can analyze financial decisions period-by-period. This will allow us to explicitly characterize the stochastic processes of prices and investment and derive the limit distribution of growth rates.

Finally, the assumption that bailout guarantees are systemic is essential. If instead, guarantees were unconditional and a bailout were granted whenever a single borrower defaulted, then the guarantees would neutralize the contract enforceability problems and borrowing constraints would not arise in equilibrium.

\subsection{Symmetric Equilibria (SE)}

We construct SE in two steps. First, we take prices $\left(p_{t}\right)$ and the likelihood of crisis $\left(1-u_{t+1}\right)$ as given, and derive the equilibrium at a point in time. We then endogeneize $p_{t}$ and $u_{t+1}$. In order to simplify notation we will set $a_{t}=1$ in (3).

The representative T-firm maximizes profits, taking goods and factor prices as given. It thus sets $p_{t} d_{t}=\alpha y_{t}$ and $v_{t}^{T} l_{t}^{T}=(1-\alpha) y_{t}$. Since consumers supply inelastically one unit of the non-reproducible factor, equilibrium T-output, consumer's income and the T-sector demand for N-goods are, respectively:

$$
y_{t}=d_{t}^{\alpha}, \quad v_{t}^{T}=[1-\alpha] y_{t}, \quad d\left(p_{t}\right)=\left[\frac{\alpha}{p_{t}}\right]^{\frac{1}{1-\alpha}}
$$

Since the consumer has access to complete capital markets and his subjective discount rate equals the risk free rate, in each period he consumes a constant fraction of his expected discounted income:

$$
c_{t}=[1-\delta] E_{t}\left(\sum_{j=0}^{\infty} \delta^{j}\left[(1-\alpha) y_{t+j}-T_{t+j}\right]\right)
$$

In any $\mathrm{SE}$ the representative N-firm's capital $\left(k_{t}\right)$ is equal to aggregate average capital $\left(\bar{k}_{t}\right)$. Thus, (5) implies that N-output equals: $q_{t+1}=\theta k_{t+1}=\theta I_{t}$. N-sector investment $\left(I_{t}\right)$ is determined by the equilibria of the credit market game, which are characterized in ST and summarized in the next proposition. 
Proposition 3.1 (Symmetric Credit Market Equilibria (CME)) There is investment in the production of $N$-goods if and only if

$$
R_{t+1}^{e}:=\beta \theta\left[u_{t+1} \frac{\bar{p}_{t+1}}{p_{t}}+\left[1-u_{t+1}\right] \frac{\underline{p}_{t+1}}{p_{t}}\right] \geq \frac{1}{\delta}>\frac{h}{u_{t+1}}
$$

Suppose (11) holds. Then,

i There always exists a 'safe' CME in which insolvency risk is hedged $\left(b_{t}=0\right)$. Credit and investment are: $b_{t}^{n}=\left[m^{s}-1\right] w_{t}$ and $I_{t}=m^{s} \frac{w_{t}}{p_{t}}$, with $m^{s}=\frac{1}{1-h \delta}$.

ii If in addition $u_{t+1}=u<1$ and $\frac{\beta \theta \underline{p}_{t+1}}{p_{t}}<\frac{h}{u}$, there also exists a 'risky' CME in which currency mismatch is optimal $\left(b_{t}^{n}=0\right)$. Credit and investment are: $b_{t}=\left[m^{r}-1\right] w_{t}$ and $I_{t}=m^{r} \frac{w_{t}}{p_{t}}$, with $m^{r}=\frac{1}{1-u^{-1} h \delta}$.

Given that all other entrepreneurs choose the safe plan (i), an entrepreneur knows that no bailout will be granted next period. Since lenders must break-even, the entrepreneur must internalize all bankruptcy costs. Thus, she will not set a diversion scheme and will hedge insolvency risk by denominating all debt in N-goods. Since the firm will never go bust and lenders must break even, the interest rate that the entrepreneur has to offer satisfies $\left[1+\rho_{t}^{n}\right] E_{t}\left(p_{t+1}\right)=1+r$. Since (11) holds, investment yields a return which is higher than the opportunity cost of capital. ${ }^{22}$ Thus, the entrepreneur will borrow up to an amount that makes the credit constraint binding: $(1+r) b_{t}^{n} \leq h\left(w_{t}+b_{t}^{n}\right)$. Substituting this borrowing constraint in the budget constraint $p_{t} I_{t}=w_{t}+b_{t}^{n}$ generates the investment equation. Notice that a necessary condition for borrowing constraints to arise is $h<1+r$. If $h$, the index of contract enforceability, were greater than the cost of capital, it would always be cheaper to repay debt rather than to divert.

Given that all other entrepreneurs choose the risky plan (ii), a young entrepreneur expects a bailout in the low state, but not in the high state. The proposition shows that, in spite of the guarantees, diversion schemes are not optimal. Thus, borrowing constraints bind. Will the entrepreneur choose T-debt or N-debt? She knows that all other firms will go bust in the bad state (i.e., $\left.\pi\left(\underline{p}_{t+1}\right)<0\right)$ provided there is insolvency risk - i.e., $\frac{\beta \theta \underline{p}_{t+1}}{p_{t}}<\frac{h}{u}$. However,

\footnotetext{
${ }^{22}$ The marginal return to investment is $E_{t}\left(p_{t+1}\right) \Theta_{t} \beta k_{t}^{\beta-1} l_{t}^{1-\beta}-\left(\delta p_{t}\right)^{-1}=E_{t}\left(p_{t+1}\right) \theta \beta-\left(\delta p_{t}\right)^{-1}$. This is because in an SE $\Theta_{t}=\theta \bar{k}_{t}^{1-\beta}, \bar{k}_{t}=k_{t}$ and $l_{t}=1$.
} 
since there are systemic guarantees, lenders will get repaid in full. Thus, the interest rate on T-debt that allows lenders to break-even satisfies $1+\rho_{t}=1+r$. It follows that the benefits of a risky plan derive from the fact that choosing $\mathrm{T}$-debt over $\mathrm{N}$-debt reduces the cost of capital from $1+r$ to $[1+r] u$. Lower expected debt repayments ease the borrowing constraint as lenders will lend up to an amount that equates $u[1+r] b_{t}$ to $h\left[w_{t}+b_{t}\right]$. Thus, investment is higher relative to a plan financed with $\mathrm{N}$-debt. The downside of a risky plan is that it entails a probability $1-u$ of insolvency. Will the two benefits of issuing T-debt-more and cheaper funding- be large enough to compensate for the cost of bankruptcy in the bad state? If there is sufficient real exchange rate variability and $u$ is not too low, expected profits under a risky plan exceed those under a safe plan: $u \pi^{r}\left(\bar{p}_{t+1}\right)>u \pi^{s}\left(\bar{p}_{t+1}\right)+(1-u) \pi^{s}\left(\underline{p}_{t+1}\right)$.

To sum up, Proposition 3.1 makes three key points. First, binding borrowing constraints arise in equilibrium and investment is constrained by cash flow, provided the production of N-goods is a positive NPV undertaking: $R_{t+1}^{e} \geq 1+r$. Second, agents optimally choose T-denominated debt if there is sufficient real exchange rate variability so that firms go bust in the low price state: $\pi\left(\underline{p}_{t+1}\right)<0$. Third, such a risky currency mismatch eases borrowing constraints and allows firms to invest more than under perfect hedging: $m^{r}>m^{s}$.

\subsubsection{Equilibrium Dynamics}

In this subsection we endogeneize prices and determine the conditions under which there is a self-validating process $\left\{p_{t}, \bar{p}_{t+1}, \underline{p}_{t+1}, u_{t+1}\right\}_{t=0}^{\infty}$ that satisfies the return conditions specified in Proposition 3.1. We start by characterizing the transition equations. If a firm is solvent, the young entrepreneur's wage equals the marginal product of her labor, while under insolvency she just obtains a share $\mu_{w}$ of revenues. Thus, in any SE the young entrepreneur's cash flow is

$$
w_{t}=\left\{\begin{array}{ll}
{[1-\beta] p_{t} q_{t}} & \text { if } \pi\left(p_{t}\right) \geq 0 \\
\mu_{w} p_{t} q_{t} & \text { if } \pi\left(p_{t}\right)<0,
\end{array} \quad \mu_{w} \in(0,1-\beta)\right.
$$

Suppose for a moment that (11) holds, so that it is optimal to invest all funds in the production of N-goods: $p_{t} I_{t}=m_{t} w_{t}$. It then follows from (12) that N-sector investment is

$$
I_{t}=\phi_{t} q_{t}, \quad \phi_{t}=\left\{\begin{array}{ll}
{[1-\beta] m_{t}} & \text { if } \pi\left(p_{t}\right) \geq 0 \\
\mu_{w} m_{t} & \text { if } \pi\left(p_{t}\right)<0,
\end{array} \quad m_{t} \in\left\{m^{s}, m^{r}\right\}\right.
$$


Since in an SE $q_{t}=\theta I_{t-1}$, it follows from (9), (13) and the market clearing condition $\left(d_{t}+I_{t}=q_{t}\right)$ that equilibrium N-output, prices and T-output evolve according to

$$
\begin{aligned}
& q_{t}=\theta \phi_{t-1} q_{t-1} \\
& p_{t}=\alpha\left[q_{t}\left(1-\phi_{t}\right)\right]^{\alpha-1} \\
& y_{t}=\left[q_{t}\left(1-\phi_{t}\right)\right]^{\alpha}=\frac{1-\phi_{t}}{\alpha} p_{t} q_{t}
\end{aligned}
$$

Clearly, for prices to be positive it is necessary that the share of N-output purchased by the $\mathrm{N}$-sector $\phi_{t}$ is less than one:

$$
h<u_{t+1} \beta \delta^{-1}
$$

Equations (13)-(16) form an SE provided the implied returns validate the agents' expectations (specified in Proposition 3.1). The next two propositions characterize two such SE: a safe one in which crises never occur, and a risky one where all firms become insolvent in the low price state and are solvent in the high price state.

Proposition 3.2 (Safe Symmetric Equilibria (SSE)) There exists an SSE if and only if the degree of contract enforceability $h$ is low enough and $N$-sector productivity $\theta$ is large enough. In an SSE there is no currency mismatch $\left(b_{t}=0\right)$ and crises never occur $\left(u_{t+1}=1\right)$. Thus, the $N$-sector investment share is $\phi^{s}=\frac{1-\beta}{1-h \delta}$.

This proposition states that an SSE exists provided enforceability problems are severe, so that there are borrowing constraints and $\phi_{t}<1$; and productivity is high enough, so that the return on investment is attractive enough.

In an SSE all entrepreneurs select the safe plan of Proposition 3.1 during every period. This implies that there is no currency mismatch in the aggregate, and self-fulfilling crises are not possible $\left(u_{t+1}=1\right)$. Therefore, the production of $\mathrm{N}$-goods has a positive net present value (i.e., (11) holds) if and only if $\frac{\beta \theta p_{t+1}}{p_{t}}=\beta \theta^{\alpha}\left(\phi^{s}\right)^{\alpha-1} \geq \delta^{-1}$. This condition, as well as (17), hold provided $h$ is low enough and $\theta$ is high enough.

Next, we characterize Risky Symmetric Equilibria (RSE). We have seen that entrepreneurs will take on T-debt only if there is enough anticipated real exchange rate variability to generate high returns in the good state and a critical mass of insolvencies in the bad state. We now reverse the question and ask instead when a risky debt structure implies enough 
real exchange rate variability. That is: $(i)$ will the low price be low enough so that there will be widespread insolvencies $\left(\pi\left(\underline{p}_{t+1}\right)<0\right)$ ? $(i i)$ will there be a sufficiently high return in the good state to ensure that the ex-ante expected return is high enough $\left(R_{t+1}^{e} \geq 1+r\right)$ ?

The following proposition provides answers to these questions, and it establishes that the self-reinforcing mechanism we described above is at work. On the one hand, expected real exchange rate variability makes it optimal for entrepreneurs to denominate debt in T-goods and run the risk of going bust. On the other hand, the resulting currency mismatch at the aggregate level makes the real exchange rate variable, validating agents' expectations.

Proposition 3.3 (Risky Symmetric Equilibrium (RSE)) There exists an RSE if and only if the probability of crisis $(1-u)$ is small enough, $N$-sector productivity $(\theta)$ is large enough, and the degree of contract enforceability $(h)$ is low, but not too low.

1. In any RSE multiple crises can occur during which all $N$-sector firms default and there is a sharp real depreciation. However, two crises cannot occur in consecutive periods.

2. In the RSE where there is a reversion back to a risky path in the period immediately after the crisis, all firms choose risky plans in no-crisis times and safe plans in crisis times. The probability of a crisis and the N-sector's investment share satisfy:

$$
1-u_{t+1}=\left\{\begin{array}{ll}
1-u & \text { if } t \neq \tau_{i} \\
0 & \text { if } t=\tau_{i}
\end{array} \quad \phi_{t}= \begin{cases}\phi^{l}:=\frac{1-\beta}{1-h \delta u^{-1}} & \text { if } t \neq \tau_{i} \\
\phi^{c}:=\frac{\mu_{w}}{1-h \delta} & \text { if } t=\tau_{i}\end{cases}\right.
$$

where $\tau_{i}$ denotes a crisis time.

A key property of the RSE characterized in Proposition 3.3 is that a crisis state is not an absorbing state: a crisis can occur every other period independently of the number of previous crises. Since we are interested in long run growth, it is essential that the economy follows a risky path for a long time. This entails having multiple crises.

To see the intuition consider a typical period $t$ and suppose that all inherited debt is denominated in T-goods and agents expect a bailout at $t+1$ in case a majority of firms goes bust. Since the debt burden is independent of prices there are two market clearing prices as in Figure 4. In the 'solvent' equilibrium (point A in Figure 4), the price is high enough to 
Figure 4: Non Tradables Market Equilibrium

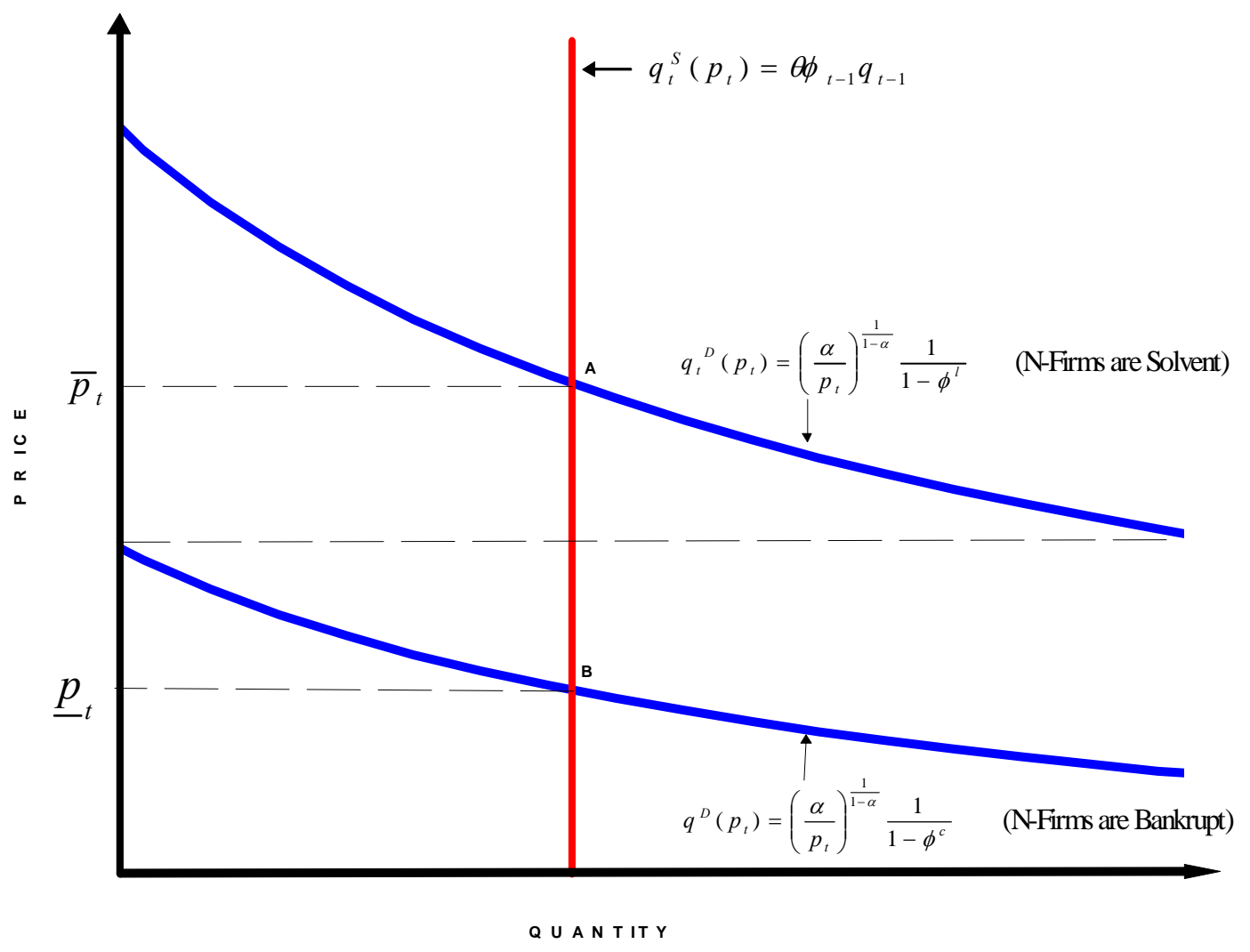


allow the N-sector to buy a large share of N-output. In contrast, in the 'crisis' equilibrium of point $\mathrm{B}$, the price is so low that $\mathrm{N}$-firms go bust: $\beta \underline{p}_{t} q_{t}<L_{t}{ }^{23}$

The key to having multiple equilibria is that part of the N-sector's demand comes from the N-sector itself. Thus, if the price fell below a cutoff level and N-firms went bust, the investment share of the N-sector would fall (from $\phi^{l}$ to $\phi^{c}$ ). This, in turn, would reduce the demand for N-goods, validating the fall in the prices. Notice that the upper bound on $h$ and the lower bound on $\theta$ ensure that when crises are rare events, borrowing constraints arise and investment is profitable (i.e., (11) holds). Meanwhile, the lower bound on $h$ ensures that firms with T-debt go bust in the bad state, and that the fall in cash flow is translated into a large fall in credit and $\mathrm{N}$-investment. This validates the fall in prices.

Two points are worth emphasizing. First, Proposition 3.3 holds for any $\mu_{w} \in(0,1-\beta)$ and $\mu \in[0, \beta]$. That is, crisis costs are not necessary to trigger a crisis. A shift in expectations is sufficient: a crisis can occur whenever entrepreneurs expect that others will not undertake credit risk, so that there is a reversion to the safe CME characterized in Proposition 3.1. Second, two crises cannot occur consecutively. Since investment in the crisis period falls, the supply of N-goods during the post-crisis period will also fall. This will drive post-crisis prices up, preventing the occurrence of insolvencies even if all debt were T-debt. That is, during the post-crisis period a drop in prices large enough to generate insolvencies is impossible.

\section{Growth and Skewness}

Here we will link Propositions 3.2 and 3.3 to our empirical findings by characterizing the growth rates of GDP and credit along risky and safe SE. Since N-goods are intermediate inputs, while T-goods are final consumption goods, gross domestic product equals the value of N-sector investment plus T-output: $g d p_{t}=p_{t} I_{t}+y_{t}$. It then follows from (13)-(16) that, in any SE, GDP is given by

$$
g d p_{t}=p_{t} \phi_{t} q_{t}+y_{t}=q_{t}^{\alpha} Z\left(\phi_{t}\right)=y_{t} \frac{Z\left(\phi_{t}\right)}{\left[1-\phi_{t}\right]}, \quad Z\left(\phi_{t}\right)=\frac{1-(1-\alpha) \phi_{t}}{\left[1-\phi_{t}\right]^{1-\alpha}}
$$

As we can see, the key determinant of the evolution of GDP is the share of N-output invested by the N-sector: $\phi_{t}$. This share is determined by the cash flow of young entrepreneurs and by

\footnotetext{
${ }^{23}$ For a discussion of the role of multiple equilibria in explaining financial crises see Cole and Kehoe (2000).
} 
the credit they can obtain. It follows from Proposition 3.1 that in an SE the credit extended to the N-sector, expressed in terms of N-goods, is given by

$$
B_{t}= \begin{cases}{\left[\phi_{t}-(1-\beta)\right] q_{t}} & \text { if } \pi\left(p_{t}\right) \geq 0 \\ {\left[\phi_{t}-\mu_{w}\right] q_{t}} & \text { if } \pi\left(p_{t}\right)<0\end{cases}
$$

\subsection{Growth in a Safe Economy}

In an SSE the investment share $\phi_{t}$ is constant and equal to $\phi^{s}$. Thus, (19) implies that GDP and T-output grow at the same rate.

$$
1+\gamma^{s}:=\frac{g d p_{t}}{g d p_{t-1}}=\frac{y_{t}}{y_{t-1}}=\left(\theta \frac{1-\beta}{1-h \delta}\right)^{\alpha}=\left(\theta \phi^{s}\right)^{\alpha}
$$

Absent exogenous technological progress in the T-sector, the endogenous growth of the Nsector is the force driving growth in both sectors. As the N-sector expands, N-goods become more abundant and cheaper allowing the T-sector to expand production. This expansion is possible if and only if N-sector productivity $(\theta)$ and the $\mathrm{N}$-investment share $\left(\phi^{s}\right)$ are high enough, so that credit and N-output can grow over time: $\frac{B_{t}}{B_{t-1}}=\frac{q_{t}}{q_{t-1}}=\theta \phi^{s}>1$. Notice that for any positive growth rate of N-output, $\gamma^{s}$ increases with the intensity of the N-input in the production of T-goods $(\alpha)$.

The mechanism by which higher growth in the N-sector induces higher growth in the $\mathrm{T}$-sector is the decline in the relative price of N-goods that takes place in a growing economy $\frac{p_{t+1}}{p_{t}}=\left[\theta \phi^{s}\right]^{\alpha-1}$. If there were technological progress in the T-sector, there would be a BalassaSamuelson effect and the real exchange rate would appreciate over time. ${ }^{24}$

\subsection{Growth in a Risky Economy}

Proposition 3.3 shows that any RSE is composed of a succession of lucky paths punctuated by crisis episodes. In the RSE characterized by (3.3) the economy is on a lucky path at time $t$ if there has not been a crisis either at $t-1$ or at $t$. Since along a lucky path the investment share equals $\phi^{l},(19)$ implies that the common growth rate of GDP and T-output is

$$
1+\gamma^{l}:=\frac{g d p_{t}}{g d p_{t-1}}=\frac{y_{t}}{y_{t-1}}=\left(\theta \frac{1-\beta}{1-h \delta u^{-1}}\right)^{\alpha}=\left(\theta \phi^{l}\right)^{\alpha}
$$

\footnotetext{
${ }^{24}$ Suppose the technological parameter in the T-production function grows over time $\frac{a_{t+1}}{a_{t}}=(1+g)$. Then price dynamics are given by $\frac{p_{t+1}}{p_{t}}=(1+g)\left[\theta \phi^{s}\right]^{\alpha-1}$.
} 
A comparison of (21) and (22) reveals that as long as a crisis does not occur, growth in a risky economy is higher than in a safe economy. Along the lucky path the N-sector undertakes insolvency risk by issuing T-debt. Since there are systemic guarantees, financing costs fall and borrowing constraints are relaxed, relative to a safe economy. This increases the Nsector's investment share $\left(\phi^{l}>\phi^{s}\right)$. Since there are sectorial linkages $(\alpha>0)$, this increase in the N-sector's investment share benefits both the T- and the N-sectors and fosters faster GDP growth.

However, in a risky economy a self-fulfilling crisis can occur with probability $1-u$, and during a crisis episode growth is lower than along a safe path. We have seen that any crisis episode consists of at least two periods: in the first period the financial position of the Nsector is severely weakened and the investment share falls from $\phi^{l}$ to $\phi^{c}<\phi^{s}$; then in the second period it jumps back to $\phi^{l}$. Since these transitions occur with certainty, the mean crisis growth rate is given by

$$
1+\gamma^{c r}=\underbrace{\left(\left(\theta \phi^{l}\right)^{\alpha} \frac{Z\left(\phi^{c}\right)}{Z\left(\phi^{l}\right)}\right)^{1 / 2}}_{\text {crisis period }} \underbrace{\left(\left(\theta \phi^{c}\right)^{\alpha} \frac{Z\left(\phi^{l}\right)}{Z\left(\phi^{c}\right)}\right)^{1 / 2}}_{\text {post-crisis period }}=\left(\theta\left(\phi^{l} \phi^{c}\right)^{\frac{1}{2}}\right)^{\alpha}
$$

The second equality in (23) shows that the average loss in GDP growth stems only from the fall in the N-sector's average investment share: $\left(\phi^{l} \phi^{c}\right)^{\frac{1}{2}}$. This reduction comes about through two channels: financial distress (indexed by $\frac{\mu_{w}}{1-\beta}$ ) and a reduction in risk taking and leverage (indexed by $\frac{1-h \delta}{1-h \delta u^{-1}}$ ). Notice that variations in GDP growth generated by real exchange rate changes at $\tau$ and $\tau+1$ cancel out. We will come back to this below.

A crisis has long-run effects because $\mathrm{N}$-investment is the source of endogenous growth, and so the level of GDP falls permanently. This raises two questions: is mean long-run GDP growth in a risky economy greater than in a safe one? Does an increase in risk taking (i.e., an increase in the probability of crisis) in a risky economy increase mean long-run GDP growth? The answers to these questions are not straightforward because an increase in the probability of crisis $(1-u)$ has opposing effects on long-run growth. One the one hand, a greater $1-u$ increases investment and growth along the lucky path by increasing the subsidy implicit in the guarantee and allowing firms to be more leveraged. On the other hand, a greater $1-u$ makes crises more frequent. Therefore, to give a precise answer to the questions 
we have raised, we compute the limit distribution of GDP's growth rate.

Figure 5 exhibits one realization of the paths of GDP, credit, T- and N-output associated with a set of parameters satisfying the conditions in Propositions 3.2 and 3.3. This figure makes clear that greater long run growth comes at the cost of (rare) crises. Notice that since N-goods are used as inputs in both sectors, higher N-sector investment leads to a lower initial level of T-ouput in a risky economy $\left(y_{0}^{l}=\left[q_{0}\left(1-\phi^{l}\right)\right]^{\alpha}<\left[q_{0}\left(1-\phi^{s}\right)\right]^{\alpha}=y_{0}^{s}\right)$. Over time, however, T-output along the risky path will overtake that in a safe path.

Growth Limit Distribution. In any RSE two crises cannot occur in consecutive periods. Here, we will derive the limit distribution of GDP's compounded growth rate $\left(\log \left(g d p_{t}\right)-\right.$ $\left.\log \left(g d p_{t-1}\right)\right)$ along the RSE characterized in Proposition 3.3. In this RSE firms undertake credit risk the period after the crisis. It follows from (18), (22) and (23) that the growth process follows a three-state Markov chain characterized by

$$
\Gamma=\left(\begin{array}{l}
\log \left(\left(\theta \phi^{l}\right)^{\alpha}\right) \\
\log \left(\left(\theta \phi^{l}\right)^{\alpha} \frac{Z\left(\phi^{c}\right)}{Z\left(\phi^{l}\right)}\right) \\
\log \left(\left(\theta \phi^{c}\right)^{\alpha} \frac{Z\left(\phi^{l}\right)}{Z\left(\phi^{c}\right)}\right)
\end{array}\right), \quad T=\left(\begin{array}{ccc}
u & 1-u & 0 \\
0 & 0 & 1 \\
u & 1-u & 0
\end{array}\right)
$$

The three elements of $\Gamma$ are the growth rates in the lucky, crisis and post-crisis states, respectively. The element $T_{i j}$ of the transition matrix is the transition probability from state $i$ to state $j$. Since the transition matrix is irreducible, the growth process converges to a unique limit distribution over the three states that solves $T^{\prime} \Pi=\Pi$. Thus, $\Pi=\left(\frac{u}{2-u}, \frac{1-u}{2-u}, \frac{1-u}{2-u}\right)^{\prime}$, where the elements of $\Pi$ are the shares of time that an economy spends in each state over the long-run. It then follows that the mean long run GDP growth rate is $E\left(1+\gamma^{r}\right)=\exp \left(\Pi^{\prime} \Gamma\right) .{ }^{25}$ That is,

$$
E\left(1+\gamma^{r}\right)=\left(1+\gamma^{l}\right)^{\omega}\left(1+\gamma^{c r}\right)^{1-\omega}=\theta^{\alpha}\left(\phi^{l}\right)^{\alpha \omega}\left(\phi^{l} \phi^{c}\right)^{\alpha \frac{1-\omega}{2}}, \quad \text { where } \omega=\frac{u}{2-u}
$$

A comparison of long run GDP growth rates in (21) and (25) reveals the trade-offs involved in following safe and risky growth paths, and allows us to determine the conditions under which credit risk is growth enhancing.

\footnotetext{
${ }^{25} E\left(1+\gamma^{r}\right)$ is the geometric mean of $1+\gamma^{l}, 1+\gamma^{l c}$ and $1+\gamma^{c l}$.
} 
Figure 5: Risky vs Safe Economy
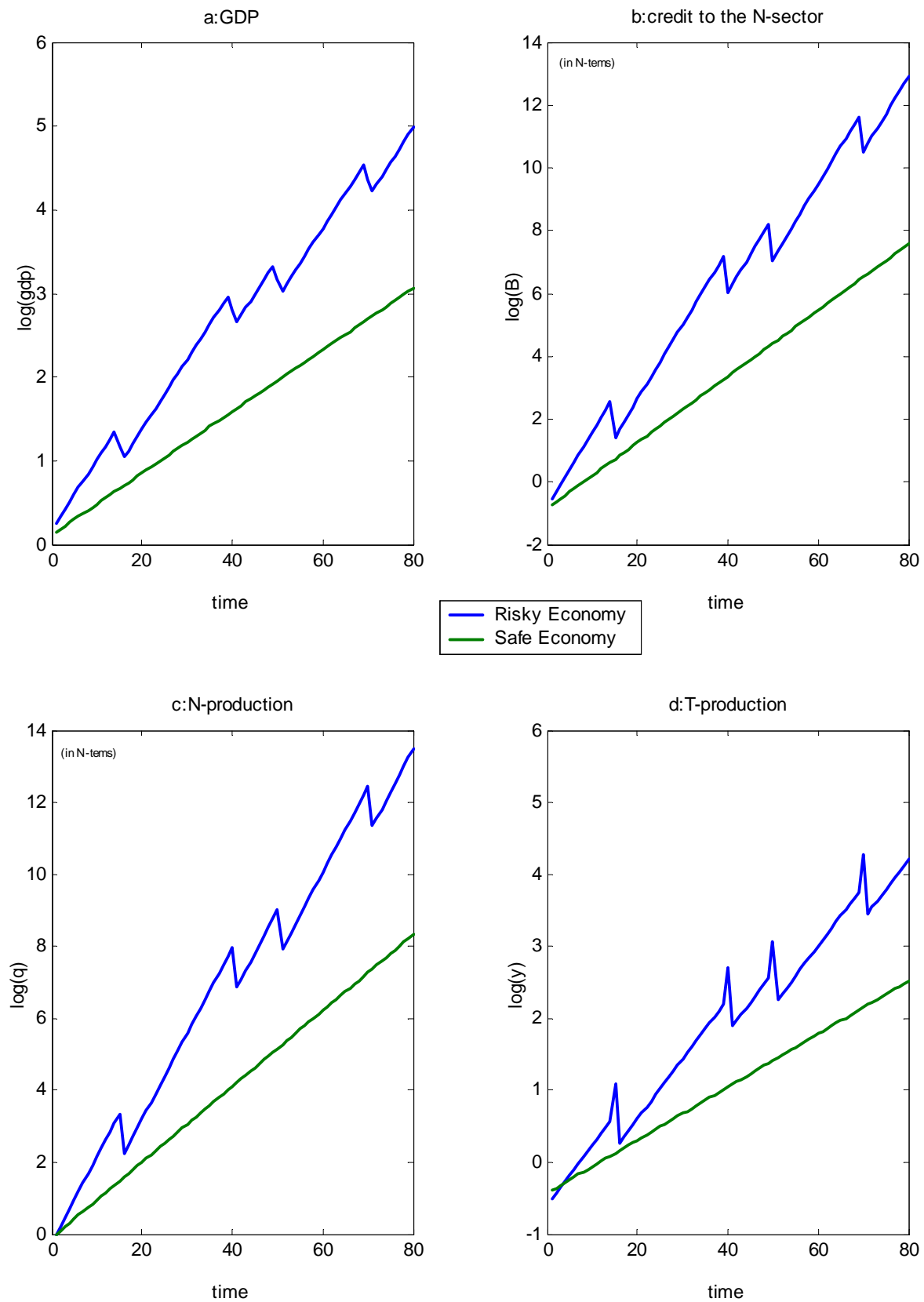

parameters : $\theta=1.65 \quad \alpha=0.35 \quad h=0.76 \quad 1-\beta=0.2 \quad l^{d}=70 \% \quad 1-u=5 \%$ 
Proposition 4.1 (Long-run GDP Growth) If financial distress during crises is not too severe $\left(l^{d} \equiv 1-\frac{\mu_{w}}{1-\beta}<\overline{l^{d}}\right)$, there exists an $h^{*}<u \beta \delta^{-1}$, such that mean long-run GDP growth is greater in a risky than in a safe equilibrium if and only if the degree contract enforceability satisfies $h>h^{*}$ :

$$
h^{*}=\frac{1-\left(1-l^{d}\right)^{1-u}}{u^{-1}-\left(1-l^{d}\right)^{1-u}} \frac{1}{\delta} \quad \overline{l^{d}}=1-\left(\frac{1-\beta}{1-\beta u}\right)^{\frac{1}{1-u}} .
$$

If $l^{d} \geq \overline{l^{d}}$, then $h^{*} \geq u \beta \delta^{-1}$ and an $R S E$ does not exist.

Rewriting $h>h^{*}$ as $(1-u)\left[\log (1-\beta)-\log \left(\mu_{w}\right)\right]<\log \left(\phi^{l}\right)-\log \left(\phi^{s}\right)$ makes clear what are the costs and benefits associated with a risky path. A risky economy outperforms a safe one if the benefits of higher investment in no-crisis times $\left(\phi^{l}>\phi^{s}\right)$ compensate for the shortfall in cash flow and investment in crisis times $\left(\mu_{w}<1-\beta\right)$ weighted by the frequency of crisis $(1-u)$.

Notice that an increase in distress costs can be compensated by an increase in the degree of contract enforceability. The latter increases leverage and amplifies the benefits of risktaking $\left(\partial \phi^{l} / \partial h>\partial \phi^{s} / \partial h\right)$. However, as $h$ is bounded above to ensure the existence of an $\operatorname{RSE}\left(\phi^{l}<1 \Leftrightarrow h<u \beta \delta^{-1}\right)$, an increase in contract enforceability can compensate for large but not arbitrarily large distress costs (i.e., $\left.\mu_{w} \rightarrow 0\right) .{ }^{26}$

Figure 6 illustrates the limit distribution of GDP growth rates by plotting different GDP paths corresponding to different realizations of the sunspot process. Most of the risky paths outperform the safe path, except for a few unlucky risky paths. If we increased the number of paths, the cross section distribution would converge to the limit distribution.

Figure 7 exhibits the two effects of an increase in the probability of crisis $(1-u)$. A reduction in $u$ increases the investment multiplier $m^{r}$ at a point in time, but it also increases the frequency of crises. The figure shows that for high $u$ the first effect dominates and the long-run mean growth rate of GDP goes up. Importantly, $u$ cannot be reduced indefinitely. After a certain point an RSE ceases to exist.

\footnotetext{
${ }^{26}$ How large can "not too large" be?

$$
1-\beta=0.2
$$

\begin{tabular}{|l|l|l|}
\hline$u$ & 0.85 & 0.99 \\
\hline$\overline{l^{d}}$ & $95.4 \%$ & $98 \%$ \\
\hline
\end{tabular}

$1-\beta=0.4$

\begin{tabular}{|l|l|l|}
\hline$u$ & 0.85 & 0.99 \\
\hline$\overline{l^{d}}$ & $74.2 \%$ & $77.4 \%$ \\
\hline
\end{tabular}
}


Figure 6: Limit Distribution of GDP

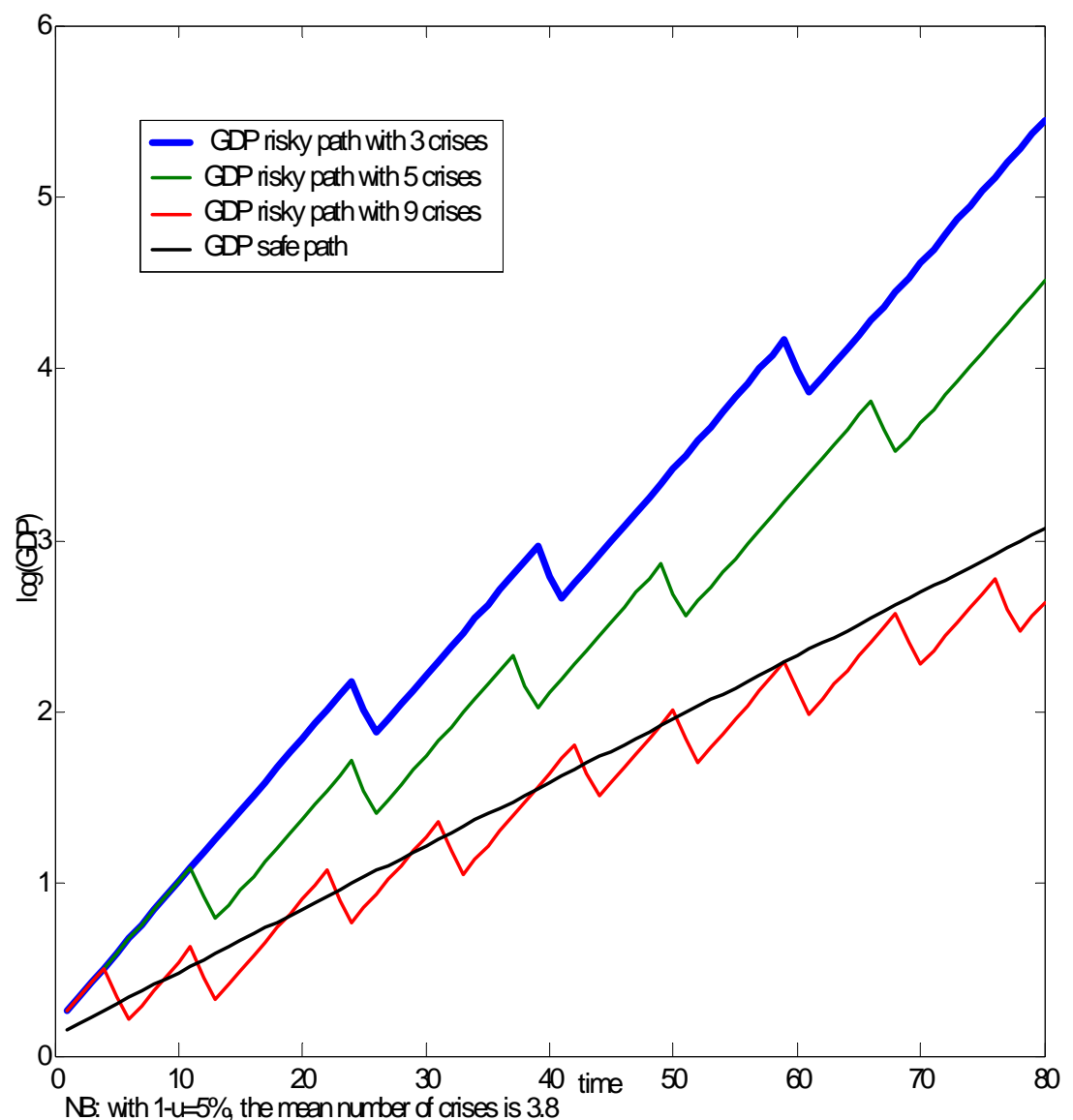

parameters $\quad: \theta=1.65 \quad \alpha=0.35 \quad h=0.76 \quad 1-\beta=0.2 \quad l^{d}=70 \% \quad 1-u=5 \%$ 
Figure 7: GDP Growth and Credit Risk

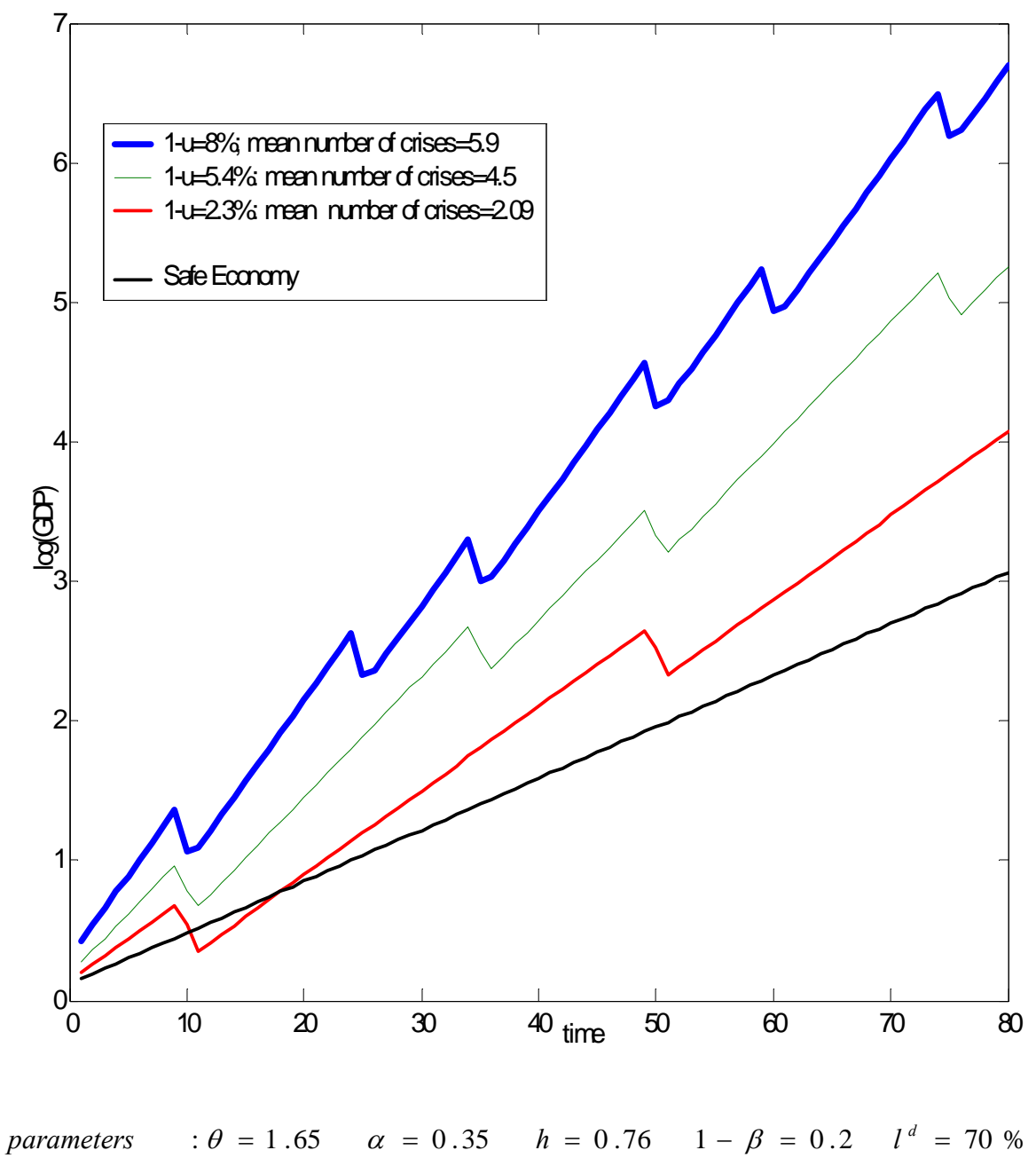


Figure 8: GDP Growth and Financial Distress Costs $\left(l^{d}=1-\frac{\mu_{w}}{1-\beta}\right)$

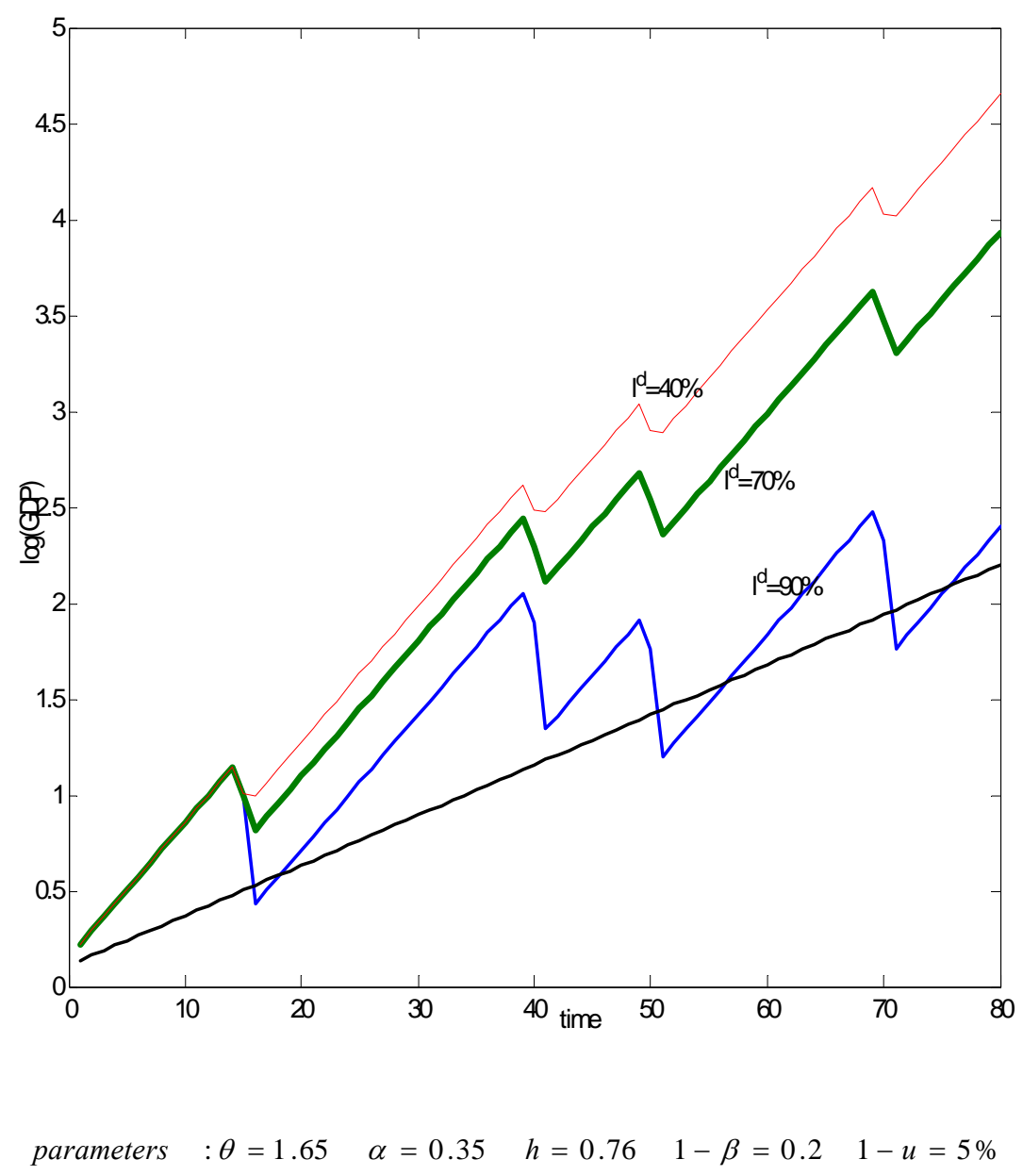

Finally, Figure 8 shows risky growth paths associated with different degrees of crisis' financial distress. As we can see, even if $90 \%$ of N-sector cash flow is lost during a crisis, a risky economy can outperform a safe economy over the long run.

A Crisis Episode. Although the main objective of the model is to address long-run issues, it is reassuring that it can account for key stylized facts of recent financial crises in MECs. In particular, the real depreciation that coincides with a sharp fall in credit growth, as well as the asymmetric sectorial response of $\mathrm{N}$ - and T-sectors.

If a self-fulfilling crisis occurs at some date, say $\tau$, there is a firesale: there is a steep real 
exchange rate depreciation, and since there is currency mismatch, all N-firms default. As a result, the investment share falls from $\phi^{l}$ to $\phi^{c} .^{27}$ The price of N-goods must fall to allow the T-sector to absorb a greater share of $\mathrm{N}$-output, which is predetermined by $\tau-1$ investment. At $\tau+1, \mathrm{~N}$-output contracts due to the fall in investment at the time of the crisis. However, entrepreneurs adopt risky plans again, so the investment share increases from $\phi^{s}$ back to $\phi^{l}$. Thus, there is a real appreciation. At $\tau+2$, the economy is back on a lucky path, but the level of cash flow and N-output are below their pre-crisis trend.

Although GDP fluctuations reflect changes in the real exchange rate, T-output and Ninvestment, and these variables move in different directions, GDP growth during a crisis episode is solely determined by the mean investment share $\left[\phi^{l} \phi^{c}\right]^{\frac{1}{2}}$ (by $(23)$ ). To understand why this is so note that GDP growth has two components: (i) real exchange rate fluctuations (captured by $\left.\frac{Z\left(\phi_{t}\right)}{Z\left(\phi_{t-1}\right)}\right)$ and (ii) output fluctuations (captured by $\left.\left(\theta \phi_{t}\right)^{\alpha}\right) .{ }^{28}$ In the crisis period, GDP growth falls below trend because there is a real exchange rate depreciation $\left(\frac{Z\left(\phi^{l}\right)}{Z\left(\phi^{c}\right)}<1\right)$. In the post crisis period, there are two effects: (i) since investment contracted during the previous period, N-output falls below trend and depresses growth; but (ii) there is a rebound of the real exchange rate as the investment share jumps from its crisis level $\left(\frac{Z\left(\phi^{c}\right)}{Z\left(\phi^{l}\right)}>1\right)$. As we can see, variations in GDP growth generated by real exchange rate changes at $\tau$ and $\tau+1$ cancel out. Thus, the average loss in GDP growth stems only from the fall in the N-sector's average investment share.

\footnotetext{
${ }^{27}$ This is because young entrepreneurs income is only $\mu_{w} p_{\tau} q_{\tau}$ instead of $[1-\beta] p_{\tau} q_{\tau}$, and at $\tau$ entrepreneurs can only choose safe plans in which there is no currency mismatch (by Proposition 3.3).

${ }^{28}$ To interpret (23) note that variations in the investment share $\phi_{t}$ have lagged and contemporaneous effects on GDP. The lagged effect comes about because a change in $\phi_{t}$ affects next period's GDP via its effect on N-output: $q_{t+1}=\theta I_{t}=\theta \phi_{t} q_{t}$. Using (19) and $y_{t}=\left(\left[1-\phi_{t}\right] q_{t}\right)^{\alpha}$, the contemporeneous effect can be decomposed as:

$$
\frac{\partial g d p_{t}}{\partial \phi_{t}}=-\frac{\alpha y_{t}}{1-\phi_{t}}+p_{t} q_{t}+q_{t} \phi_{t} \frac{\partial p_{t}}{\partial \phi_{t}}=q_{t} \phi_{t} \frac{\partial p_{t}}{\partial \phi_{t}}
$$

The first two terms capture variations in T-output and N-investment, while the third reflects real exchange rate fluctuations. Market clearing in the $\mathrm{N}$-goods market -i.e., $\left(1-\phi_{t}\right) p_{t} q_{t}=\alpha y_{t}$-implies that the induced changes in N-sector investment and T-output cancel out. Therefore, the contemporeneous changes in the investment share affect GDP contemporaneously only through its effect on the real exchange rate. Since $G D P_{t}=Z\left(\phi_{t}\right) q_{t}^{\alpha}$, we can express $q_{t} \phi_{t} \frac{\partial p_{t}}{\partial \phi_{t}}$ as $q_{t}^{\alpha} \frac{\partial Z_{t}}{\partial \phi_{t}}$. Thus, we can interpret $\frac{Z\left(\phi_{t}\right)}{Z\left(\phi_{t-1}\right)}$ as the effect of real exchange rate fluctuations on GDP.
} 
In sum, a crisis has two distinct effects: sectorial redistribution and deadweight losses. At the time of the crisis the T-sector benefits from the financial collapse of the N-sector because it can buy N-output at firesale prices and expand production. This leads to a sharp fall in the N-to-T output ratio in the wake of crisis. The deadweight losses derive from the financial distress and the bankruptcy costs implied by crises. The former leads to a contraction in N-investment and thus has a long-run effect on output. In contrast, bankruptcy costs have only a static fiscal impact.

\subsection{Credit Growth}

Here, we derive testable implications regarding the link between bumpiness and growth. We start by showing that the skewness of credit growth is a good indicator of the riskiness of an economy's credit path. We then combine this result with Proposition 4.1 to interpret our empirical results.

It follows from (20) that in an RSE the limit distribution of the compounded growth rate of credit is characterized by

$$
\zeta=\left(\begin{array}{l}
\zeta^{l}=\log \left(\theta \phi^{l}\right) \\
\zeta^{c}=\log \left(\theta \phi^{l} u \frac{\mu_{w}}{1-\beta} \frac{1-h \delta u^{-1}}{1-h \delta}\right) \\
\zeta^{p}=\log \left(\theta \phi^{l} \frac{1}{u}\right)
\end{array}\right), \quad \Pi=\left(\begin{array}{c}
\frac{u}{2-u} \\
\frac{1-u}{2-u} \\
\frac{1-u}{2-u}
\end{array}\right)
$$

As before, the elements of $\Pi$ are the shares of time that the economy spends in each state. It follows that

Proposition 4.2 (Skewness) The limit distribution of credit growth in a risky symmetric equilibrium exhibits negative skewness

$$
\frac{E(\zeta-\bar{\zeta})^{3}}{\sigma^{3}}=\left[d^{2}(2(1-\omega)-1)-3\right] \frac{[1-\omega] \omega d}{\sigma^{3} D^{3}}<0
$$

where $d=\frac{\left(\zeta^{l}-\zeta^{c}\right)-\left(\zeta^{p}-\zeta^{l}\right)}{\zeta^{p}-\zeta^{c}}<1, D:=\frac{\zeta^{p}-\zeta^{c}}{2}>0$ and $\omega=\frac{u}{2-u}$.

In an RSE N-firms face endogenous borrowing constraints, and so N-sector credit is constrained by cash flow. Since along the lucky path -in which no crises occur- cash flow accumulates gradually, credit can grow only gradually. In contrast, when a crisis erupts 
Figure 9: Kernel Distribution of Credit Growth
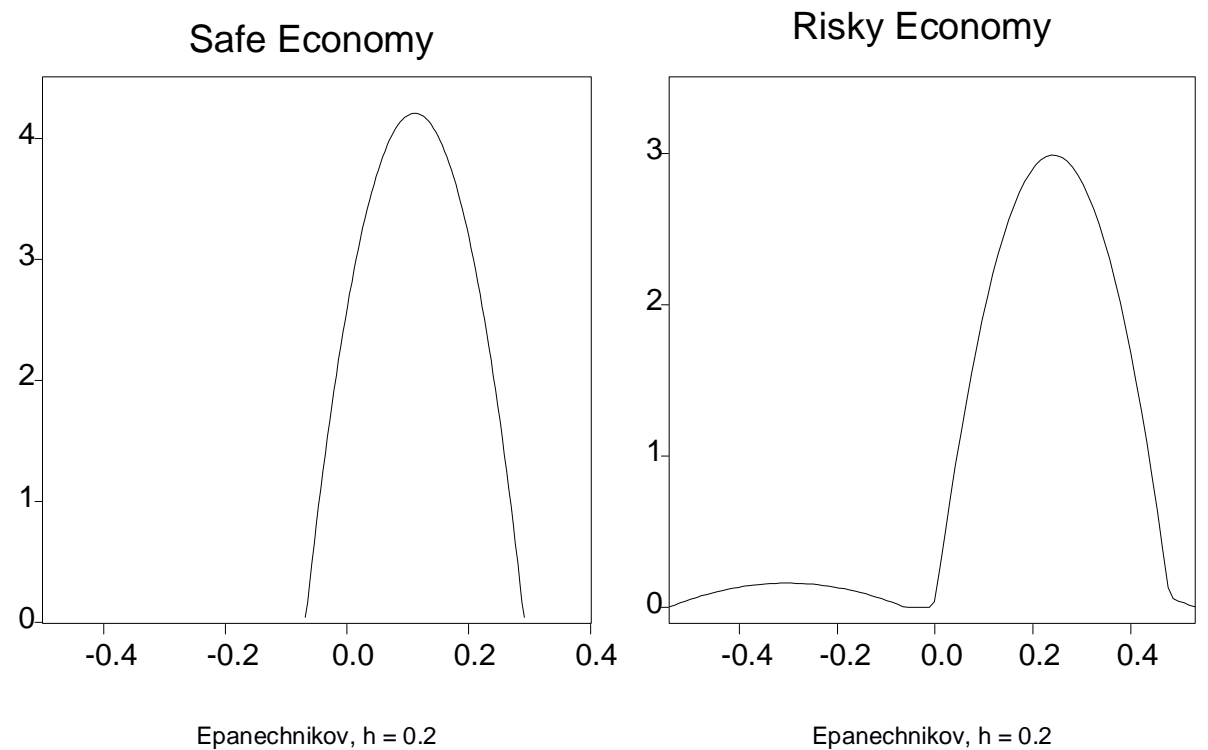

there are widespread bankruptcies and cash flow collapses. Thus, credit growth falls sharply $\left(\zeta^{c}<\zeta^{l}\right)$. In the wake of crisis credit growth rebounds before returning to its level in normal times $\left(\zeta^{p}>\zeta^{c}\right)$.

On the one hand, as long as crises are rare events, the credit growth rates during the post-crisis period and the lucky path are very close $\left(\zeta^{p}-\zeta^{l}\right)=\log \left(u^{-1}\right)$. On the other hand, the fall in cash-flow $\left(\frac{1-\beta}{\mu_{w}}\right)$ and in the investment multiplier $\left(\frac{m^{r}}{m^{s}}\right)$ that occur during a crisis generate a sharp fall in credit:

$$
\zeta^{l}-\zeta^{c}=\log \left(\frac{1-\beta}{\mu_{w}}\right)+\log \left(\frac{m^{r}}{m^{s}}\right)+\log \left(\frac{1}{u}\right)>\zeta^{p}-\zeta^{c}>0
$$

The point made by Proposition 4.2 is that since falls and rebounds occur with the same frequency, (28) translates into a negatively skewed credit growth rate distribution. That is, in a long enough sample, the distribution of $\zeta$ is characterized by negative outliers.

Figure 9 exhibits the kernel distribution of credit growth for safe and risky economies for the same set of parameter values as in Figure 5. As we can see, there is a remarkable similarity between these distributions and those of India and Thailand in Figure 2. 


\subsubsection{From Model to Data}

The degree of contract enforceability $h$ is key in our model. Recall from Propositions 3.1 and 3.2 that borrowing constraints arise in equilibrium only if contract enforceability problems are severe: $h<\bar{h}=u \beta \delta^{-1}$. In borrowing constrained economies, credit risk can arise only if $h>\underline{h}$ (Proposition 3.3). Furthermore, credit risk increases average long-run growth only if $h>h^{*}$ (Proposition 4.1). Thus, credit risk may be growth-enhancing only in the set of countries where contract enforceability problems are severe, but not too severe: $h \in$ $\left(\max \left\{\underline{h}, h^{*}\right\}, \bar{h}\right)$. Within this set of economies, a negatively skewed credit growth distribution identifies those that have followed a risky credit path (by Proposition 4.2).

Notice that if enforceability problems were either not severe or too severe, there would be no endogenous force to make growth rates negatively skewed to begin with. Thus, the link between negative skewness and growth would not exist. This argument underlies our sample selection rule in the empirical section.

In other words, if credit risk is introduced into an economy with severe, but not too severe, credit market imperfections and a lending boom is set in motion, then average GDP growth may increase. However, higher average growth comes at the cost of negative skewness because the boom will be punctuated by rare busts. If this were not the case -i.e., busts either never occurred or they were very frequent- then the boom would not start in the first place. Whether growth is greater in a risky economy depends on the magnitude of crisis costs. This is an empirical question that the regressions in Section 2 address.

In our model, growth rates exhibit more variance in the risky economy than in the safe one. Empirically, however, the variance is not a good instrument for identifying economies that have followed growth-enhancing risky credit paths that lead to infrequent crises. This is because higher variance of credit and output growth may also reflect high frequency shocks, which may be exogenous or may be self-inflicted by, for instance, bad economic policy. In our setup, greater mean GDP growth is not associated with higher variance of credit growth generated by high frequency shocks.

In sum, in order to uncover the link between bumpiness and growth, it is essential to distinguish infrequent busts from high frequency shocks. Both lead to higher variance, but only the former leads to negative skewness. This is why the empirical part of the paper uses 
the skewness of credit growth and not the variance, as a measure of bumpiness.

\section{Production Efficiency and Welfare}

We have considered an endogenous growth model where the financially constrained N-sector is the engine of growth because it produces the intermediate input used throughout the economy. Thus, the share of N-output invested in the N-sector, $\phi_{t}$, is the key determinant of economic growth. When $\phi_{t}$ is too small T-output is high in the short-run, but long-run growth is slow. In contrast, when $\phi_{t}$ is too high, there is inefficient accumulation of N-goods. In this section we ask three questions. First, what is the Pareto optimal N-investment share sequence $\left\{\phi_{t}\right\}$ ? Second, can this Pareto optimal investment sequence be replicated in a safe equilibrium? If not, can ex-ante social welfare be higher in a risky economy where agents undertake credit risk and crises can occur? Third, is such a welfare improving reallocation implementable? In particular, will consumers be willing to foot the bill to finance the bailout guarantees associated with a risky economy?

\subsection{Pareto Optimality}

In our set-up, $\mathrm{N}$-goods are intermediate inputs, while T-goods are final consumption goods. Consider then a central planner who maximizes social welfare by investing the supply of $\mathrm{N}$-goods in the T-sector $\left(\left[1-\phi_{t}\right] q_{t}:=d_{t}\right)$ and the N-sector $\left(\phi_{t} q_{t}\right)$, as well as by assigning sequences of T-goods to consumers and entrepreneurs for their consumption:

$$
\begin{aligned}
\max _{\left\{c_{t}, c_{t}^{e}, \phi_{t}\right\}_{t=0}^{\infty}} \sum_{t=0}^{\infty} \delta^{t}\left[[1-\nu] u\left(c_{t}\right)+\nu c_{t}^{e}\right], \quad \text { s.t. } \quad & \sum_{t=0}^{\infty} \delta^{t}\left[c_{t}+c_{t}^{e}-y_{t}\right] \leq 0 \\
& y_{t}=\left[1-\phi_{t}\right]^{\alpha} q_{t}^{\alpha}, \quad q_{t+1}=\theta \phi_{t} q_{t}
\end{aligned}
$$

Clearly, Pareto optimality implies efficient accumulation of N-inputs: because optimal consumption is a function of the present value of income, the planner should choose the investment sequence $\left\{\phi_{t}\right\}$ to maximize the present value of T-production: $\sum_{t=0}^{\infty} \delta^{t} y_{t}$. We show in the Appendix that the Pareto optimal N-investment share is constant and equal to

$$
\phi^{p o}=\left(\theta^{\alpha} \delta\right)^{\frac{1}{1-\alpha}}, \quad \text { if } \quad \alpha<\log \left(\delta^{-1}\right) / \log (\theta)
$$


The Pareto optimal share equalizes the discount rate $\delta^{-1}$ to the intertemporal rate of transformation. A marginal increase in the N-sector investment share $(\partial \phi)$ reduces today's T-output by $\alpha\left[(1-\phi) q_{t}\right]^{\alpha-1} \partial \phi$, but increases tomorrow's N-output by $\theta \partial \phi$ and tomorrow's T-output by $\alpha\left[(1-\phi) \theta \phi q_{t}\right]^{\alpha-1} \theta \partial \phi$. Thus, at an optimum $\theta^{\alpha} \phi^{\alpha-1}=\delta^{-1}$.

Can a decentralized economy replicate the Pareto optimal allocation? The optimal Ninvestment share is determined by investment opportunities: $\theta^{\alpha} \delta$. In contrast, in a decentralized safe economy the N-investment share $\left(\phi^{s}=\frac{1-\beta}{1-h \delta}\right)$ is determined by the degree of contract enforceability $(h)$ and by the N-sector's cash flow $(1-\beta)$. Therefore, if either $h$ or $1-\beta$ are low, the $\mathrm{N}$-sector investment share will be lower than the Pareto optimal share: $\phi^{s}<\phi^{p o}$. That is, when the N-sector is severely credit constrained, low N-sector investment will keep the economy below production efficiency. For future reference we summarize with the following Proposition.

Proposition 5.1 (Bottleneck) N-sector investment in a safe economy is below the Pareto optimal level (i.e., there is a 'bottleneck') if there is low contract enforceability: $h<(1-$ $\left.(1-\beta) \theta(\theta \delta)^{-\frac{1}{1-\alpha}}\right) \delta^{-1}$.

When there is a bottleneck, the share of N-inputs allocated to T-production should be reduced and that allocated to N-production should be increased. This reallocation reduces the initial level of T-output, but increase its growth rate and the present value of cumulative T-production. Can the adoption of credit risk induce this reallocation and bring the economy nearer to the Pareto optimum? Is there a sense in which social welfare increases? Recall that along a lucky path of an RSE the investment share is greater than the share in a safe economy. However, credit risk through currency mismatch makes the economy vulnerable to crises, which entail deadweight losses for the economy. In the next subsection, we consider the effects of crises and ask whether ex-ante welfare in a risky economy is greater than in a safe economy.

\subsection{Social Welfare}

In our model economy consumers have access to complete financial markets and their discount rate equals the riskless interest rate, so their consumption is constant over time. Furthermore, 
N-sector entrepreneurs are risk-neutral. Thus, we can measure ex-ante social welfare with the expected discounted sum of consumers and entrepreneurs' consumption:

$$
W=E_{0}\left(\sum_{t=0}^{\infty} \delta^{t}\left(c_{t}+c_{t}^{e}\right)\right)=E_{0}\left(\sum_{t=0}^{\infty} \delta^{t}\left[(1-\alpha) y_{t}+\pi_{t}-T_{t}\right]\right)
$$

To derive the second equation in (31) notice that in equilibrium consumers' income is $[1-\alpha] y_{t}$, entrepreneurs' income is equal to their profits $\pi_{t}$, and the fiscal cost of bailouts is financed with lump-sum taxes. At any $t \geq 1$ profits equal old entrepreneurs share in revenues minus debt repayments: $\pi_{t}=\beta p_{t} q_{t}-L_{t}=\frac{\alpha}{1-\phi^{s}} \beta y_{t}-\frac{\alpha}{1-\phi^{s}} \frac{h}{u} \phi^{s} y_{t-1}$. Meanwhile, since at $t=0$ there is no debt burden, $\pi_{0}=\frac{\alpha}{1-\phi^{s}} \beta y_{0}$.

In a safe economy firms are always solvent and crises never occur. Thus, there are no bailouts and no taxes. It then follows from (31) that social welfare equals the present value of T-output

$$
W^{s}=\sum_{t=0}^{\infty} \delta^{t} y_{t}^{s}=\frac{1}{1-\delta\left(\theta \phi^{s}\right)^{\alpha}} y_{o}^{s}=\frac{\left(1-\phi^{s}\right)^{\alpha}}{1-\delta\left(\theta \phi^{s}\right)^{\alpha}} q_{o}^{\alpha} \quad \text { if } \delta\left(\theta \phi^{s}\right)^{\alpha}<1
$$

Consider a risky economy. Along the lucky path, the investment share is greater than in a safe economy. Thus, if there is a bottleneck and crises are rare events, the present value of T-output along the lucky path is greater than in a safe path. However, along a lucky path a crisis can occur with probability $1-u$. The question then arises as to whether it is worthwhile to incur the crisis costs in order to attain higher T-output growth.

A crisis involves three costs. First, there is a fiscal cost. Lenders receive a bailout payment equal to the debt repayment they were promised: $L_{\tau}=u^{-1} h \phi^{l} p_{\tau-1} q_{\tau-1}$. Since the bailout agency recuperates only a share $\mu \leq \beta$ of firms revenues $p_{\tau} q_{\tau}$, while the rest is dissipated in bankruptcy procedures, the fiscal cost of a crisis is $T(\tau)=L_{\tau}-\mu p_{\tau} q_{\tau}$. Second, investment falls: in a crisis the investment share is $\phi^{c}=\frac{\mu_{w}}{1-h \delta}$ instead of $\phi^{s}$ in a safe economy. During crisis borrowing constraints are tighter than in a safe economy because an N-firm's net worth is $\mu_{w} p_{\tau} q_{\tau}$ instead of $[1-\beta] p_{\tau} q_{\tau}$ and risk taking is curtailed: only safe plans are financed. Finally, since during a crisis all N-firms go bust, old entrepreneurs' profits are zero.

The deadweight loss of a crisis for the economy as a whole is lower than the sum of these three costs. During a crisis there is a sharp redistribution from the N- to the T-sector generated by a severe real depreciation (a firesale). Thus, some of the costs incurred in the N-sector show up as greater T-output and consumers' income. We show in the Appendix that 
after netting out the costs and redistributions, a crisis involves two deadweight losses: (i) the revenues dissipated in bankruptcy procedures: $[\beta-\mu] p_{\tau} q_{\tau}$; and (ii) the fall in N-sector investment due to its weakened financial position: $\left[(1-\beta)-\mu_{w}\right] p_{\tau} q_{\tau}$. Using the market clearing condition $\alpha y_{t}=\left[1-\phi_{t}\right] p_{t} q_{t}$, we have that the sum of these two deadweight losses equals $\frac{\alpha}{1-\phi^{c}}\left[1-\mu-\mu_{w}\right] y_{\tau}$ in terms of T-goods. Thus, in an RSE social welfare is given by

$$
W^{r}=E_{0} \sum_{t=0}^{\infty} \delta^{t} k_{t} y_{t}, \quad k_{t}= \begin{cases}k^{c}:=1-\frac{\alpha\left[1-\mu-\mu_{w}\right]}{1-\phi^{c}} & \text { if } t=\tau_{i} \\ 1 & \text { otherwise }\end{cases}
$$

where $\tau_{i}$ is a crisis time. In order to compute this expectation we need to calculate the limit distribution of $k_{t} y_{t}$. We do this in the Appendix and show that ex-ante welfare in a risky economy is

$$
W^{r}=\frac{1+\delta(1-u)\left[\theta \phi^{l} \frac{1-\phi^{c}}{1-\phi^{l}}\right]^{\alpha} k^{c}}{1-\left[\theta \phi^{l}\right]^{\alpha} \delta u-\left[\theta^{2} \phi^{l} \phi^{c}\right]^{\alpha} \delta^{2}(1-u)}\left[\left(1-\phi^{l}\right) q_{0}\right]^{\alpha}
$$

By comparing (32) and (34) we can determine the conditions under which ex-ante welfare is greater in a risky economy. The next Proposition provides a sufficient condition for credit risk to be welfare improving.

Proposition 5.2 (Social Welfare) If crises are rare events and the costs of crises $(\beta / \mu$, $\left.(1-\beta) / \mu_{w}\right)$ are small, then ex-ante social welfare in a risky economy is greater than in a safe economy if and only if there is a bottleneck $\left(\phi^{s}<\phi^{p o}\right)$.

If crises entail small bankruptcy costs $(\mu \rightarrow \beta)$ and mild financial distress $\left(\mu_{w} \rightarrow 1-\beta\right)$, the only first order effect of a crisis is to reduce transitorily the N-sector's investment share from $\phi^{l}$ to what it would have been in a safe economy $\left(\phi^{s}\right)$. Thus, in this limit case the investment share in the risky economy would never be lower than in the safe one. Hence, if there is a 'bottleneck' $\left(\phi^{s}<\phi^{p o}\right)$ and crises are rare events, the greater average investment share will increase the present value of T-output and hence welfare.

Small crisis costs are sufficient, but not necessary, for the result stated in Proposition 5.2. Welfare in a risky economy can be greater than in a safe one even if crisis costs are large. Figure 10 shows the welfare differential between safe and risky economies $\left(W^{r}-W^{s}\right)$ for different bankruptcy costs $\left(l^{b}=1-\frac{\mu}{\beta}\right)$ and financial distress costs $\left(l^{d}=1-\frac{\mu_{w}}{1-\beta}\right)$. As we can see, the welfare gains can be positive even if $100 \%$ of revenues are dissipated in bankruptcy 
Figure 10: Social Welfare and Crisis Costs

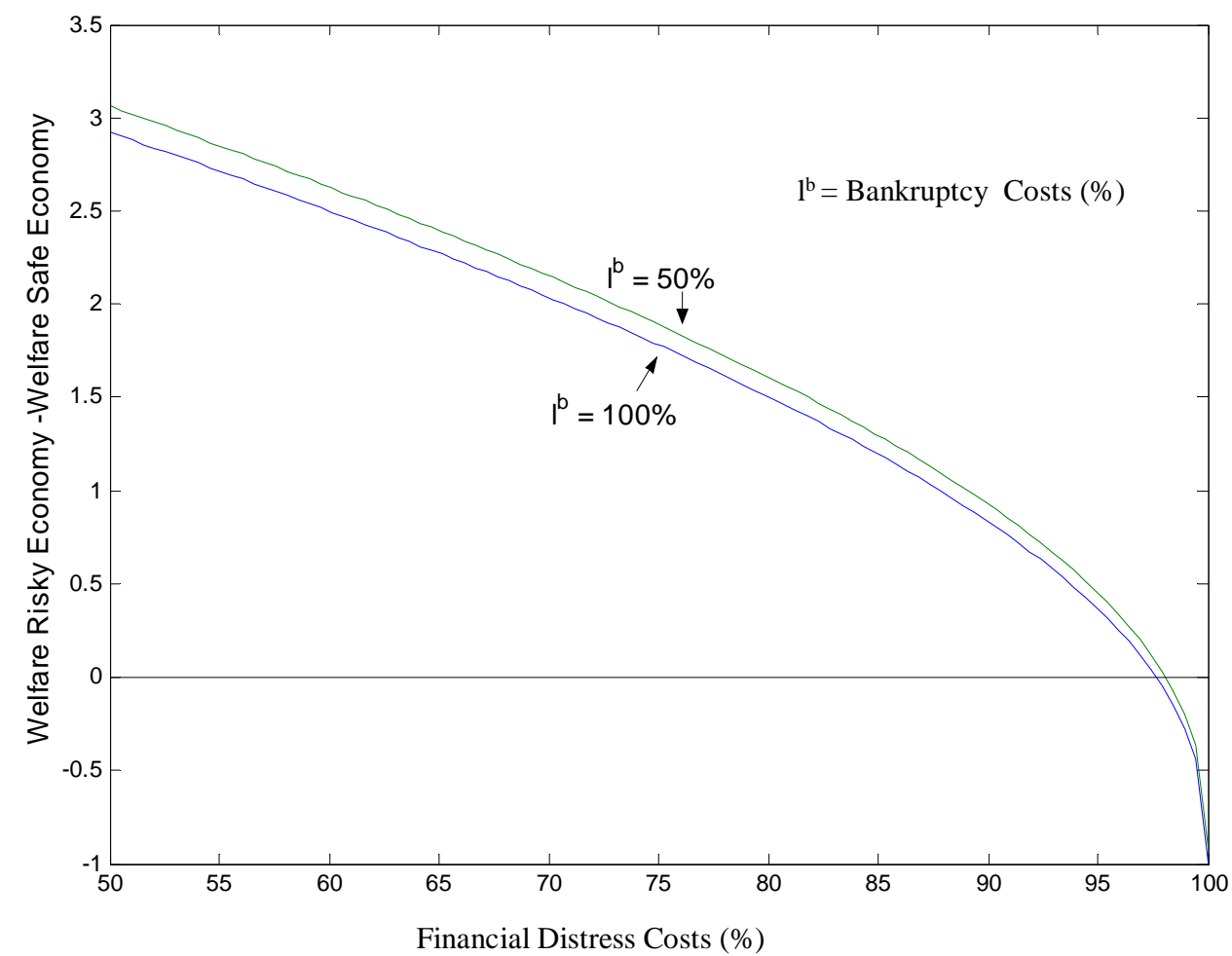

parameters $: \theta=1.65 \quad \alpha=0.35 \quad h=0.76 \quad 1-\beta=0.2 \quad 1-u=5 \%$ 
procedures $(\mu \rightarrow 0)$. There can also be positive welfare gains for severe financial distress costs $\left(l^{d}=80 \%\right)$. However, they are negative when $l^{d} \rightarrow 100 \%$. The reason for this asymmetry is that bankruptcy costs are a static loss, while financial distress costs have dynamic effects. In our endogenous growth set-up, the reduction in N-sector investment shifts the growth paths of both sectors downwards. Such an unrecoverable long term loss reduces the discounted sum of T-production over the whole post-crisis period. ${ }^{29}$ By contrast, welfare gains are almost insensitive to bankruptcy costs.

The welfare gain associated with undertaking credit risk is increasing in the probability of crisis $(1-u)$. This does not mean that this probability can be arbitrarily large. As we have discussed earlier, an RSE exists only if crises are rare events. In panel (a) of Figure 11, we show how $W^{r}-W^{s}$ varies over a range of crisis probabilities between 0 and $8 \%$. Except when the financial distress cost of crises is very high, the risky economy dominates the safe economy. This difference is amplified by a limited increase in credit risk. In contrast, if crisis costs are very large, $W^{r}-W^{s}<0$ and any increase in risk reduces $W^{r}$ further. Finally, panel (b) of Figure 11 shows that the social welfare gains are increasing in the intensity of N-inputs in T-production $(\alpha)$. A greater $\alpha$ strengthens the sectorial linkage and thus increases the welfare benefits of relaxing the borrowing constraint in the N-sector.

\subsection{Implementability}

Proposition 5.2 has established that social welfare can be greater in a risky economy even if bailout costs are funded domestically via lump-sum taxes. Systemic bailout guarantees are necessary to induce agents to undertake insolvency risk (through currency mismatch). We have seen that such a risky strategy eases borrowing constraints and leads to a greater mean growth of N-output even along a path where crises do occur. As a result, T-production will enjoy cheaper and more abundant $\mathrm{N}$-inputs, and its growth rate will also increase. This benefits consumers because they receive a share $1-\alpha$ of T-output as income.

But, is a bailout scheme implementable? Will consumers be willing to foot the bill? In particular, will consumers at date zero be willing to purchase an insurance that promises to

\footnotetext{
${ }^{29} \mathrm{~A}$ second order welfare cost of crises is the variability in the level of investment (shift from $\phi^{l}$ to $\phi^{c}$ and back). Recall that the Pareto optimal investment share is constant.
} 
Figure 11: Social Welfare Gains and Credit Risk

a. For different levels of Financial Distress Costs

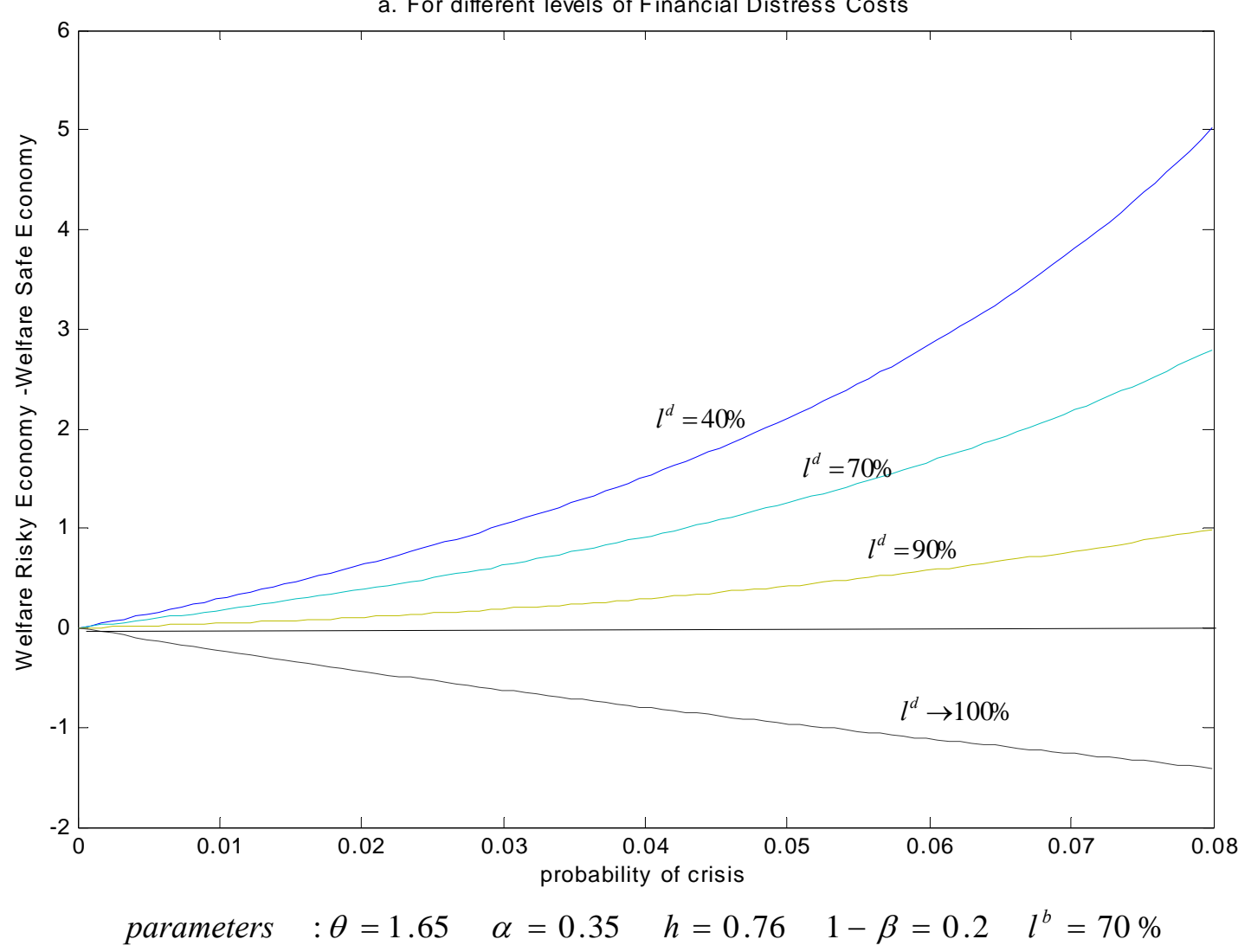

b: for different intensities of Non-Tradables Input in Tradable Production

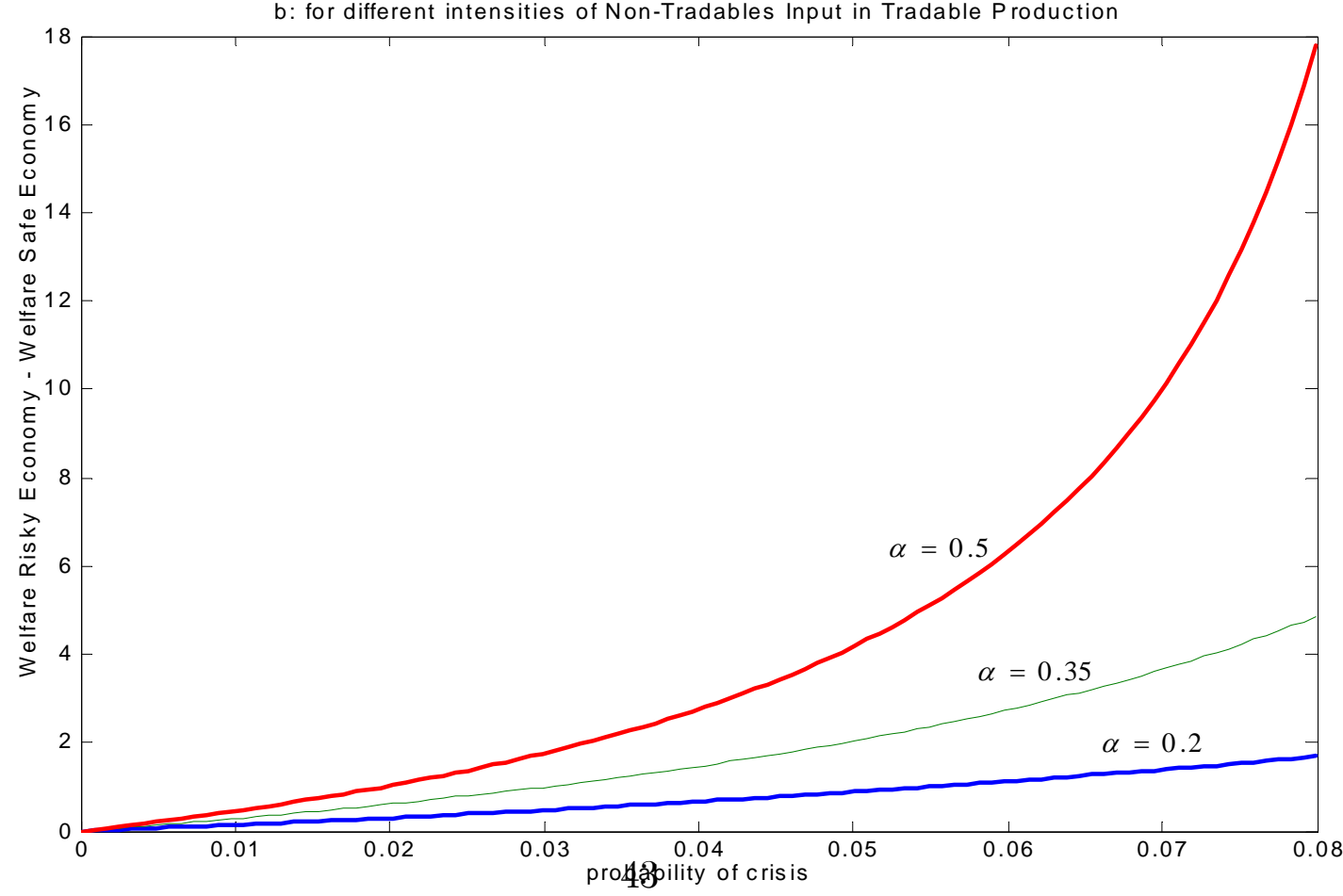

parameters $: \theta=1.65 \quad h=0.76 \quad 1-\beta=0.2 \quad l^{d}=l^{b}=70 \%$ 
cover any future bankruptcy costs associated with the guarantees? Since the representative consumer has access to complete capital markets, he can perfectly smooth the cost of the guarantees. His life time budget constraint is: $E_{0} \sum_{t=0}^{\infty} \delta^{t}\left[c_{t}-(1-\alpha) y_{t}+T_{t}\right] \leq 0$, where $T_{t}$ is the tax that will finance the bailouts. Since the consumer's share in T-output is $1-\alpha$, his ex-ante welfare in a safe and a risky economy are, respectively:

$$
C^{s}=[1-\alpha] W^{s}, \quad C^{r}=E_{0} \sum_{t=0}^{\infty} \delta^{t}\left(y_{t}[1-\alpha]-T_{t}\right)
$$

The consumer will be willing to finance the bailout if and only if $C^{s}>C^{r}$ :

$$
\frac{1+\delta(1-u)\left[\theta \phi^{l} \frac{1-\phi^{c}}{1-\phi^{l}}\right]^{\alpha} K_{c}^{T}}{1-u\left[\theta \phi^{l}\right]^{\alpha} \delta-[1-u]\left[\theta^{2} \phi^{l} \phi^{c}\right]^{\alpha} \delta^{2}}\left[\left(1-\phi^{l}\right) q_{0}\right]^{\alpha}>\frac{\left[\left(1-\phi^{s}\right) q_{0}\right]^{\alpha}}{1-\delta\left(\theta \phi^{s}\right)^{\alpha}}
$$

where $K_{c}^{T}$ is defined in (52) in the Appendix. The funding of the guarantees by consumers operates a redistribution from the non-constrained T-sector to the constrained N-sector. If (36) holds, such a redistribution is to the mutual benefit of both sectors. It is a Paretoimproving policy. Figure 12 exhibits the consumer's net welfare gain when he finances all the bailout costs for $1-\alpha=0.35 \%$. By comparing Figures 11 and 12 we can see that when social welfare gains are present, consumers welfare gains are also present, but in a smaller proportion.

\section{Related Literature.}

Our empirical findings are related to the literature that links financial liberalization to financial deepening and growth. In particular, Beckaert et.al. (2001) find that countries that have liberalized their stock markets grow faster than other countries. Chari and Henry (2002) find similar evidence at the firm level. Levine (2001) shows that financial opening fosters growth by increasing stock market liquidity and the efficiency of the banking system. Kaminsky and Schmukler (2002) show that the long-run gains associated with better functioning financial markets may come at the cost of excessive volatility in the short run. These results stress the positive effect of financial liberalization on financial deepening and the resulting increase in long run growth. They do not imply however that financial openness is growth-enhancing 
Figure 12: Consumers Welfare Gains net of Bailout Costs

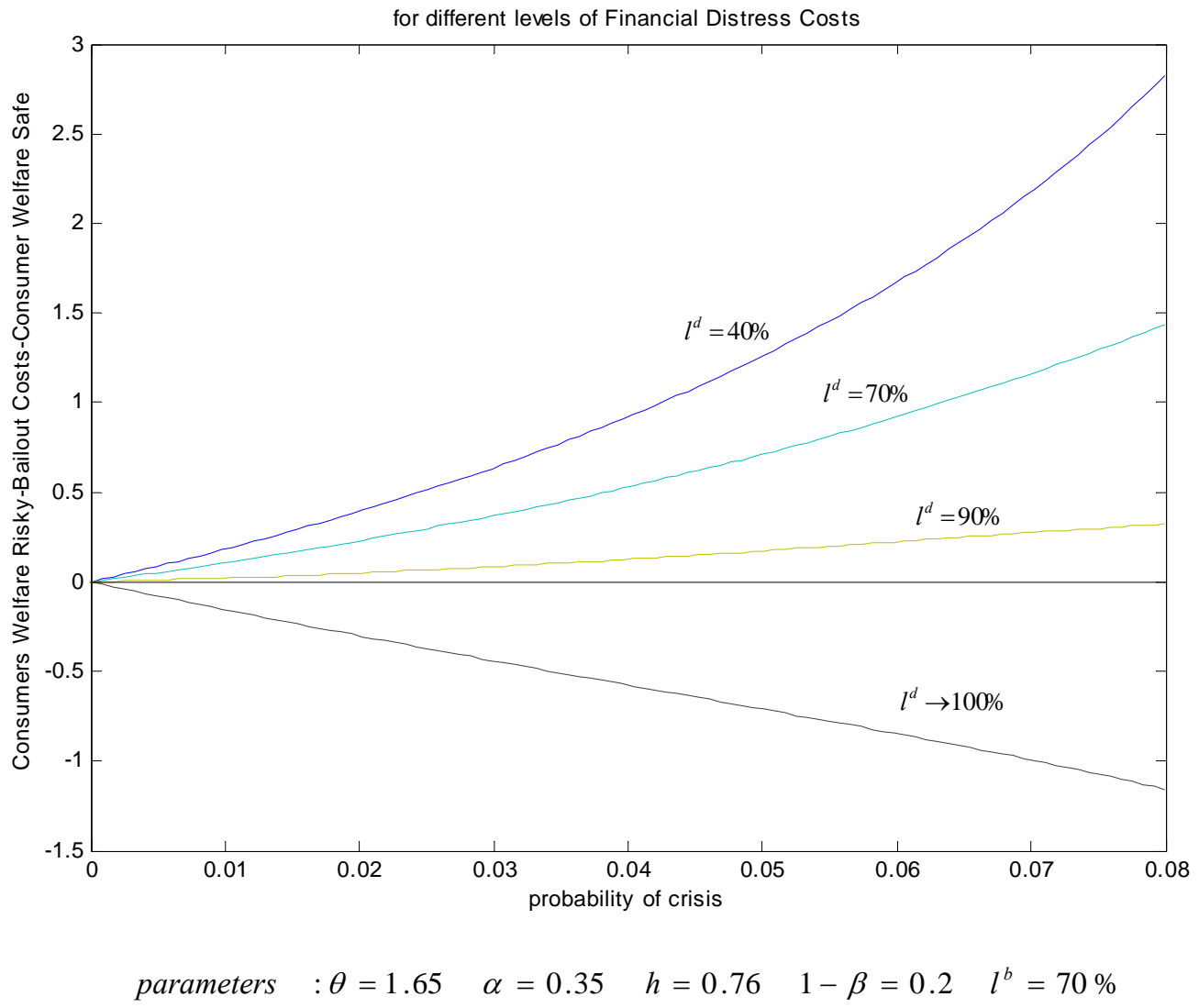

across all sets of countries. In particular, they do not contradict the findings such as Rodrik (1998) that openness does not per se accelerate growth. ${ }^{30}$

Our finding that negative skewness of credit growth correlates positively with growth is linked with Imbs (2002) finding that aggregate volatility is bad growth, while sectorial volatility is good for growth. In our setup sectorial volatility arises because the credit constrained sector undertakes credit risk as a means to increase investment. Levine and Renelt (1991) and Ramey and Ramey (1995) find that the variance of some macroeconomic aggregates is negatively associated to growth. This is not inconsistent with our findings, as the variance of credit growth also enters our regressions with a negative sign.

In using skewness to proxy for the occurrence of occasional crises our paper is linked to

\footnotetext{
${ }^{30}$ See Prasad, et. al. (2003) for an empirical synthesis of the link between financial openess and growth.
} 
papers in Finance that use the skewness of returns to identify busts (e.g. Veldkamp (2000)).

In the neoclassical growth literature financial openness increases growth and welfare by allowing faster accumulation of capital and consumption smoothing (Barro, et. al. (1995)). Gourinchas and Jeanne (2003) show that the welfare benefits associated with this mechanism are negligible in comparison to the increase in domestic productivity. Obstfeld (1994) demonstrates that domestic productivity gains occur when international risk-sharing allows a shift from safe to risky projects. In our framework the gains also stem from an increase in production efficiency not from international risk sharing. The gains are obtained by reducing the contract enforceability problem not the incomplete markets problem: welfare gains are obtained by letting entrepreneurs take on more risk, not by having consumers face less risk. In Tirole (2000b) foreign debt denomination also results in social welfare gains, but through a discipline effect on government policy.

In our model the cycle equilibrium ("the risky economy") outperforms the pure trend equilibrium ("the safe economy") in terms of mean growth and welfare. A similar result is found in Matsuyama (1999) where the economy evolves along "Solow type" paths of high investment and "Romer type" paths of high innovation; in Jovanovic (2003) where cycles are generated by the risky adoption of new technology; and in Francois and Ellis (2003) where endogenous clustering in innovation and implementation generates growth-enhancing cycles.

The credit cycles in this paper are different from Schumpeter's (1934) cycles in which the adoption of new technologies plays a key role. Our cycles are more similar to Juglar's credit cycles. Juglar $(1862,1863)$ characterized asymmetric credit cycles along with the periodic occurrence of crises in France, England, and United States over 1794-1859 as a distinctive feature of fast developing economies. ${ }^{31}$

In emphasizing that financial development leads both to higher long run growth and to more short term vulnerability to financial crises this paper is related to Loayza and Ranciere (2001) and Gaytan and Ranciere (2002). In addressing the effects of financial liberalization in the presence of asymmetric financing opportunities, this paper relates to Rajan and Zingales (1998). They show that financial development favors the sectors that are more dependent

\footnotetext{
31 "The regular development of wealth does not occur without pain and resistance. In crises everything stops for a while but it is only a temporary halt, prelude to the most beautiful destinies." Juglar (1863), page 13 (our translation).
} 
on external finance.

In studying the role of agency problems in emerging markets this paper connects with Bernanke, et.al. (2000), Mckinnon and Pill (1998), Tirole (2002a), and third generation crises models like Schneider and Tornell (2003) and the references therein. Our model differs from the Schneider and Tornell (ST) model in that we consider the interaction of two productive sectors ( $\mathrm{N}$ and $\mathrm{T}$ ), we characterize the long-run growth path of an economy that can experience several crises, and we make an explicit welfare analysis. Instead, ST concentrate on how the interaction of contract enforceability problems systemic bailout guarantees generate financial fragility and a boom-bust episode. In ST there are no productive linkages as T-output is exogenous, there is no link between skewness and growth because only one crisis occurs in equilibrium and there is no welfare analysis.

The growth enhancing effect of real-exchange rate risk-taking by the constrained sector shares some similarities with the role of bubbles in the recent literature. Ventura (2002) shows that stochastic bubbles on useless assets can boost growth by shifting resources from inefficient to efficient investors, while introducing financial fragility. Ollivier (2000) finds that bubbles on real assets can foster growth by encouraging investment in the R\&D sector, and thus can be seen as a subsidy to research. A speculative element is also present in our framework. However, in our setup there are no bubbles. Our risky equilibria are sustainable over the infinite horizon. Our results depend on the presence of bottlenecks and do not exploit any form of dynamic inefficiency. Finally, the mechanism we present is reminiscent of the literature on risk as a factor of production as Sinn (1986) and Konrad (1992).

\section{Conclusions}

We have shown that there is a strong empirical link between growth and negative skewness of credit growth across countries with significant contract enforceability problems (MECs). That is, MECs that have experienced booms and busts have grown on average faster than countries with smooth credit conditions.

We have shown theoretically that in an economy with severe credit market imperfections, the adoption of credit risk is a means to overcome the obstacles to growth by easing financing 
constraints. However, as a side effect financial fragility arises and thus crises occur from time to time. In other words, the trade-off is not fragility versus no fragility. The trade-off is: fragility and growth versus no fragility and no growth.

We have established conditions under which the welfare costs of crises are outweighed by the benefits of higher growth. Furthermore, we have established conditions under which the unconstrained tradables sector will find it profitable to fund the systematic bailout guarantees that support the risky credit path along which the constrained nontradables sector grows faster. Under this scheme the tradables sector can also grow faster because it faces less severe bottlenecks (i.e., more abundant nontradables inputs).

Our results should provide a caution when interpreting the effects of financial liberalization. From the finding that liberalization has lead to more bumpiness, one should not conclude that liberalization per se is bad either for growth or for welfare. Furthermore, policies intended to eliminate risk taking and fragility might have the unintended effect of blocking the forces that generate financial deepening and growth.

Finally, one point of clarification is in order. One should differentiate the onset of a crisis, the tipping point, from a full-blown crisis. Typically, in the wake of a tipping point authorities try to delay the inevitable and avoid the necessary real depreciation - as was the case in both Mexico 1994 and Argentina 2001. The resultant full-blown crisis ends up being much more severe than what is necessary. We would like to emphasize that the results of this paper do not justify this type of betting for resurrection.

\section{Appendix}

\section{A. Proofs and Derivations}

Proof of Proposition 3.2. In an SSE, during every period, all entrepreneurs choose the safe plan characterized in Proposition 3.1. Each entrepreneur will find it optimal to do so provided a majority of entrepreneurs chooses a safe plan and the marginal return to investment in the production of N-goods is no lower than $1+r: R_{t+1}^{e}:=\frac{\beta \theta p_{t+1}^{e}}{p_{t}} \geq \delta^{-1}$. Since in an SSE crises never occur, prices are deterministic: $u_{t+1}=1$ and $p_{t+1}^{e}=p_{t+1}$. Using (14) and (15) it follows that $R_{t+1}^{e}=\beta \theta^{\alpha}\left(\phi^{s}\right)^{\alpha-1}$. Thus, an SSE exists if and only if $\beta \theta^{\alpha}\left(\phi^{s}\right)^{\alpha-1}>\delta^{-1}$ and (17) holds. These two conditions are equivalent to

$$
h<\bar{h}=\beta \delta^{-1}, \quad \theta>\underline{\theta}=\left[\delta \beta\left(\phi^{s}\right)^{\alpha-1}\right]^{-1 / \alpha}
$$


Proof of Proposition 3.3. The proof is in two parts. In part A we consider the case in which two crises do not occur in consecutive periods. Then, in part B we show that two crises cannot occur in consecutive periods.

Part A. Consider an RSE in which all entrepreneurs choose the risky plan characterized in Proposition 3.1 during every period, except when a crisis erupts, in which case they choose safe plans. In a no-crisis period, given that all other entrepreneurs choose a risky plan, an entrepreneur will find it optimal to do so if and only if $R_{t+1}^{e}:=u \beta \theta \frac{\bar{p}_{t+1}}{p_{t}} \geq 1+r$, and $\pi\left(\underline{p}_{t+1}\right)<0$. To determine whether these conditions hold note that in an RSE the investment share $\phi_{t+1}$ equals $\phi^{l}$ if N-firms are solvent, while $\phi_{t+1}=\phi^{c}$ if they are insolvent. Replacing these expressions in the equations for cash flow (12), N-output (14) and prices (15), it follows that

$$
\begin{aligned}
& R_{t+1}^{e} \geq \frac{1}{\delta} \Leftrightarrow u \bar{R}(u)+\left[1-u \underline{R}(u) \geq \frac{1}{\delta}, \quad \bar{R}(u):=\beta \theta^{\alpha}\left[\frac{1}{\phi^{l}}\right]^{1-\alpha}\right. \\
& \pi\left(\underline{p}_{t+1}\right)<0 \Leftrightarrow \underline{R}(u)<\frac{h}{u}, \quad \underline{R}(u):=\beta \theta^{\alpha}\left[\frac{1}{\phi^{l}}\right]^{1-\alpha}\left[\frac{1-\phi^{l}}{1-\phi^{c}}\right]^{1-\alpha}
\end{aligned}
$$

To derive (39) we have used $\pi\left(\underline{p}_{t+1}\right)=\beta \underline{p}_{t+1} q_{t+1}-L_{t+1}=\beta \alpha\left[1-\phi^{c}\right]^{\alpha-1}\left[\theta \phi^{c} q_{t}\right]^{\alpha}-u^{-1} h \alpha[1-$ $\left.\phi^{l}\right]^{\alpha-1} q_{t}^{\alpha}$. Consider next a crisis period. Given that all other entrepreneurs choose a safe plan, an entrepreneur will find it optimal to do so if and only if $R_{t+1}^{e}:=\beta \theta p_{t+1}^{e} / p_{t} \geq \delta^{-1}$. Since in the post-crisis period there can be no crisis, it follows from the proof of Proposition 3.2 that this condition is equivalent to $\beta \theta^{\alpha}\left(\phi^{s}\right)^{\alpha-1} \geq \delta^{-1}$. Clearly, this condition is implied by (38). It follows that there exists an RSE where two crises do no occur in consecutive periods if and only if (38) and (39) hold and parameters satisfy (17), which is given by

$$
h \delta<u \beta
$$

"Only if." We prove that an RSE exists only if $u>\underline{u}, \theta>\bar{\theta}$, and $\underline{h}<h<\bar{h}$ in three steps. Step 1. For any $\theta \in \Re^{+}$and any $h \in \Re^{+}$there exists no RSE if $u \rightarrow 0$. To prove this, let $u \rightarrow 0$. Since $\theta$ is bounded and $1-\beta<\phi^{l}<1$, it follows that $\lim _{u \rightarrow 0^{+}} u \bar{R}(u)=0$. Therefore, (38)-(40) imply that when $u \rightarrow 0$ an RSE exists if and only if $\frac{h}{u}<\frac{\beta}{\delta}$ and $\frac{1}{\delta}<\underline{R}(u)<\frac{h}{u}$, which is a contradiction. 
Step 2. For any $u \in(0,1)$ and for any $\theta \in \Re^{+}$there exists no RSE if $h>\underline{h}$ or $h<\bar{h}$, where

$$
\bar{h}=\frac{\beta u}{\delta}, \quad \underline{h}=\frac{1}{\delta}\left(\left(\frac{1-\phi^{c}}{1-\phi^{l}}\right)^{1-\alpha}+\left(\frac{1}{u}-1\right)\right)^{-1}, \quad 0<\underline{h}<\bar{h}
$$

Notice that $h<\bar{h}$ is equivalent to (40), and that (38) and (39) hold if and only if $\delta^{-1}\left(u+(1-u)\left[\frac{1-\phi^{l}}{1-\phi^{c}}\right]\right.$ $\bar{R}(u)<\frac{h}{u}\left[\frac{1-\phi^{l}}{1-\phi^{c}}\right]^{\alpha-1}$, which holds only if $h>\underline{h}$.

Step 3. For any $u \in(0,1)$ and for any $h \in \Re^{+}$there exists no RSE if $\theta<\underline{\theta}$, where

$$
\underline{\theta}=\left(\frac{\underline{h}}{u \beta}\left[\phi^{l}\right]^{1-\alpha}\left[\frac{1-\phi^{c}}{1-\phi^{l}}\right]^{1-\alpha}\right)^{1 / \alpha}
$$

Notice that $u \bar{R}(u)+(1-u) \underline{R}(u)$ is decreasing in $h$ and an RSE exist only if $h>\underline{h}$. Thus, a necessary condition for an RSE to exist is $u \bar{R}(u)+(1-u) \underline{R}(u)\rfloor_{h=\underline{h}}>\delta^{-1}$, which is equivalent to (42).

"If." To establish the existence of an RSE we show that when $u \rightarrow 1$ parameter restrictions (38), (39) and (40) are mutually consistent if $(\theta, h) \in S=\left\{(\theta, h) \in R_{+}^{2} \mid \theta>\underline{\theta}, h^{\prime}<h<h^{\prime \prime}\right\}$, with $\underline{h} \leq h^{\prime}<h^{\prime \prime} \leq \bar{h}$. We do this in two steps. First, we allow for an upper bound $\theta<\theta_{d}(h)$. Then, we replace $\theta<\theta_{d}(h)$ by tighter bounds on $h$.

Step 1. We show that for any $\delta \in(0,1), \alpha \in(0,1)$, and $\mu_{w} \in(0,1-\beta)$ an RSE exists if $(\theta, h) \in S^{\prime}=\left\{(\theta, h) \in R_{+}^{2} \mid \underline{h}<h<\bar{h}, \theta_{n}(h)<\theta<\theta_{d}(h)\right\}$. Let $u=1$, for any $\delta \in(0,1)$ and $\alpha \in(0,1)$, (40) holds iff $h<\bar{h}=\beta \delta^{-1}$ and (38) holds iff $\theta \geq \theta_{d}(h)=\left[\delta \beta\left(\phi^{s}\right)^{\alpha-1}\right]^{-1 / \alpha}$. Next, if $u=1$, (39) becomes $\left[\frac{1-\phi^{s}}{1-\phi^{c}}\right]^{1-\alpha}<h \frac{\left(\phi^{s}\right)^{1-\alpha}}{\beta \theta^{\alpha}}$. This condition holds for any $\mu_{w} \in(0,1-\beta)$, $h<\bar{h}$ and $\theta>\theta_{n}(h)$ iff

$$
\theta<\theta_{d}(h)=\left(\left[\frac{1-\phi^{c}}{1-\phi^{s}} \frac{1}{\phi^{s}}\right]^{1-\alpha} \frac{h}{\beta}\right)^{1 / \alpha} \quad \text { and } \quad h>\underline{h}=\frac{1}{\delta}\left[\frac{1-\phi^{s}}{1-\phi^{c}}\right]^{1-\alpha}
$$

Notice that $h>\underline{h}$ is necessary for $\theta_{n}(h)<\theta_{d}(h)$ and that $\underline{h}$ is unique. Furthermore, $\theta_{n}(h)<\theta_{d}(h) \Leftrightarrow h-\frac{1}{\delta}\left[\frac{1-\phi^{s}}{1-\phi^{c}}\right]^{1-\alpha}>0$. This expression is strictly increasing in $h$, it is satisfied if $h \rightarrow \bar{h}$ and violated if $h=0$. This ensures existence and unicity of a lower bound $\underline{h}$.

Step 2. We show that the sets $S^{\prime}$ and $S$ are equivalent. Consider the following three properties of $\theta_{n}(h)$ and $\theta_{d}(h)$ over $(\underline{h}, \bar{h})$, which are illustrated in the figure below: (i) $\theta_{n}(h)<\theta_{d}(h)$; 
(ii) $\theta_{n}(h)$ and $\theta_{d}(h)$ are continuous and strictly increasing in $h$; and (iii) $\theta_{n}(\underline{h})=\theta_{d}(\underline{h})=$ $\underline{\theta} ; \lim _{h \rightarrow \bar{h}} \theta_{n}(h)=\infty$ and $\lim _{h \rightarrow \bar{h}} \theta_{d}(h)=\left(\beta \delta^{-1}\right)^{1 / \alpha}$. It follows that for any $(\theta, h) \in S^{\prime}, \theta>\underline{\theta}$ and $h \in\left(h^{\prime}, h^{\prime \prime}\right)$, where $h^{\prime}=\theta_{n}^{-1}(\theta)$ and $h^{\prime \prime}=\min \left(\theta_{n}^{-1}(\theta), \bar{h}\right)$ where $\theta^{-1}()$ denotes the inverse function. Since $\underline{h} \leq h^{\prime}<h^{\prime \prime} \leq \bar{h}$, we have that $(\theta, h) \in S^{\prime} \Rightarrow(\theta, h) \in S$. Similarly, for any $(\theta, h) \in S, \underline{h}<h<\bar{h}$ and $\theta_{n}(h)<\theta<\theta_{d}(\theta)$. Therefore, $(\theta, h) \in S \Rightarrow(\theta, h) \in S^{\prime}$.

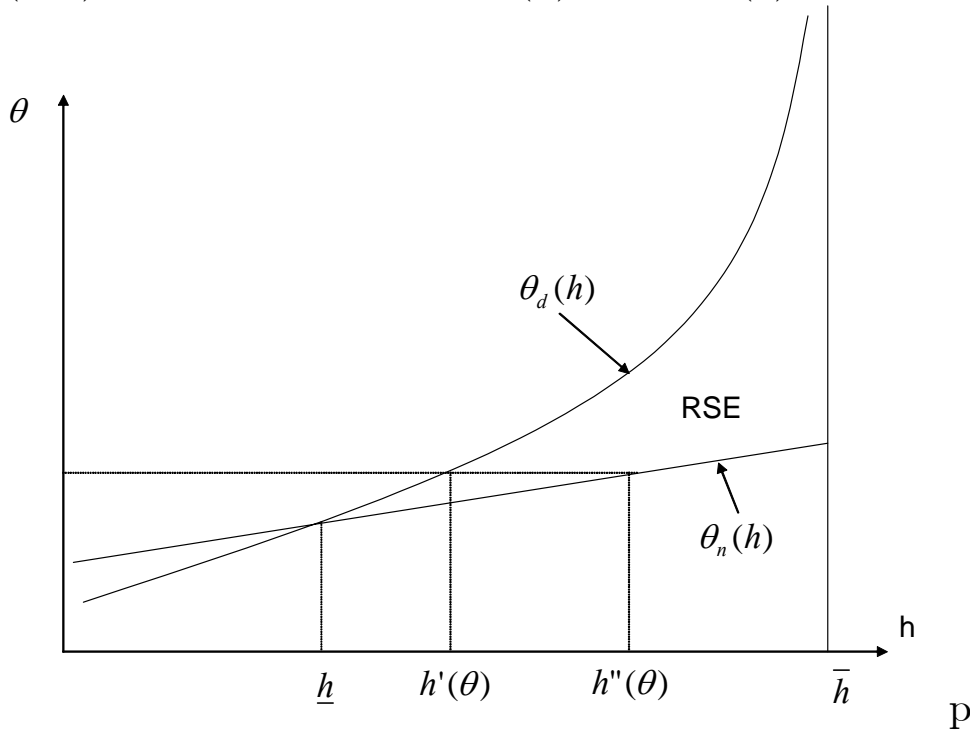

Part B. We prove by contradiction that two crises cannot occur in consecutive periods. Suppose that if a crisis occurs at $\tau$, firms choose risky plans at $\tau$. We will show that it is not possible, under any circumstances, for firms to become insolvent in the low price state at $\tau+1$ (i.e., $\left.\pi\left(\underline{p}_{\tau+1}\right)<0\right)$. It suffices to consider the case in which firms undertake safe plans at $\tau+1$, as $\underline{p}_{\tau+1}$ is the lowest in this case. Along this path the N-investment share equals $\phi_{\tau}=\tilde{\phi}^{c}:=$ $\mu_{w} m^{r}$ and $\phi_{\tau+1}=\phi^{c}:=\mu_{w} m^{s}$. Thus, $\pi\left(\underline{p}_{\tau+1}\right)=\beta \alpha\left[1-\phi^{c}\right]^{\alpha-1}\left[\theta \tilde{\phi}^{c} q_{\tau}\right]^{\alpha}-u^{-1} h \alpha\left[1-\phi^{c}\right]^{\alpha-1} q_{\tau}^{\alpha}$, and

$$
\tilde{\pi}\left(\underline{p}_{\tau+1}\right)<0 \Leftrightarrow \beta \theta^{\alpha}\left[\frac{1-\tilde{\phi}^{c}}{1-\phi^{c}} \frac{1}{\tilde{\phi}^{c}}\right]^{1-\alpha}<\frac{h}{u}
$$

Notice that the LHS of (38) is strictly lower than the LHS of (44) because: (i) $\mu_{w}<1-\beta$, so $\frac{1-\tilde{\phi}^{c}}{\tilde{\phi}^{c}}>\frac{1-\phi^{c}}{\phi^{c}}$; and (ii) $\phi^{l}>\phi^{c}$. However, the RHS of (38) is strictly higher than the RHS of (44) because $u>h \delta$ is necessary for an RSE to exist. This is a contradiction. $\not$

Proof of Proposition 4.1. We derive first the limit distribution of the growth rate process $\Delta \log \left(g d p_{t}\right):=\log \left(g d p_{t}\right)-\log \left(g d p_{t-1}\right)$. Since in an RSE crises cannot occur in two consecutive periods, $\Delta \log \left(g d p_{t}\right)$ follows a three-state Markov chain characterized by the following growth 
vector and transition matrix

$$
\Gamma=\left(\begin{array}{l}
\log \left(\left(\theta \phi^{l}\right)^{\alpha}\right) \\
\log \left(\left(\theta \phi^{l}\right)^{\alpha} \frac{Z\left(\phi^{c}\right)}{Z\left(\phi^{l}\right)}\right) \\
\log \left(\left(\theta \phi^{c}\right)^{\alpha} \frac{Z\left(\phi^{l}\right)}{Z\left(\phi^{c}\right)}\right)
\end{array}\right) \quad T=\left(\begin{array}{ccc}
u & 1-u & 0 \\
0 & 0 & 1 \\
u & 1-u & 0
\end{array}\right)
$$

Since the transition matrix is irreducible, the growth process converges to a unique limit distribution over the three states that solves $T^{\prime} \Pi=\Pi$. Thus, $\Pi^{\prime}=\left(\frac{u}{2-u}, \frac{1-u}{2-u}, \frac{1-u}{2-u}\right)$ and the geometric mean long run GDP growth rate -equation (25) in the text- is $E\left(1+\gamma^{r}\right)=$ $\exp \left(\Pi^{\prime} \Gamma\right)$. It then follows from (21) and (25) that

$$
\gamma^{r}>\gamma^{s} \Leftrightarrow\left(\frac{\mu_{w}}{1-\beta}\right)^{1-u}>\frac{1-h \delta u^{-1}}{1-h \delta} \Leftrightarrow h>\bar{h}^{\prime}:=\frac{1}{\delta} \frac{1-\left(\frac{\mu_{w}}{1-\beta}\right)^{1-u}}{\frac{1}{u}-\left(\frac{\mu_{w}}{1-\beta}\right)^{1-u}}
$$

Notice that an RSE exists only if $h<\bar{h}=u \beta / \delta$. Thus, $\bar{h}^{\prime}<\bar{h}$ if and only if $\frac{\mu_{w}}{1-\beta}>$ $\left(\frac{1-\beta}{1-\beta u}\right)^{\frac{1}{1-u}} \cdot$.

Proof of Proposition 4.2. It follows from limit distribution (27) that the mean, variance and skewness of the growth rate of credit are

$$
\begin{aligned}
& \bar{\zeta} \equiv E(\zeta)=\left[\omega \zeta_{n}+\frac{1-\omega}{2}\left(\zeta_{c}+\zeta_{p}\right)\right] \theta \phi^{l}, \\
& \sigma^{2} \equiv E(\zeta-\bar{\zeta})^{2}=\left[\omega\left(\zeta_{n}-\bar{\zeta}\right)^{2}+\frac{1-\omega}{2}\left[\left(\zeta_{p}-\bar{\zeta}\right)^{2}+\left(\zeta_{c}-\bar{\zeta}\right)^{2}\right]\right. \\
& s k \equiv \frac{E(\zeta-\bar{\zeta})^{3}}{\sigma^{3}}=\left[\omega\left(\zeta_{n}-\bar{\zeta}\right)^{3}+\frac{1-\omega}{2}\left[\left(\zeta_{p}-\bar{\zeta}\right)^{3}+\left(\zeta_{c}-\bar{\zeta}\right)^{3}\right]\right] \frac{1}{\sigma^{3}}
\end{aligned}
$$

Let $l=\zeta_{n}-\frac{\zeta_{c}+\zeta_{p}}{2}, L=\frac{\zeta_{p}-\zeta_{c}}{2}, d:=\frac{l}{L}$, so that $\zeta_{n}-\bar{\zeta}=\frac{1-\omega}{2} l, \bar{\zeta}-\zeta_{c}=L+\omega l$, and $\zeta_{p}-\bar{\zeta}=L-\omega l$. Then,

$$
\begin{aligned}
\bar{\zeta} & =L+\omega l \\
\sigma^{2} L^{2} & =\omega[(1-\omega) d]^{2}+\frac{1-\omega}{2}\left([1-\omega d]^{2}+[1+\omega d]^{2}\right)=(1-\omega)\left[1+\omega d^{2}\left[(1-\omega)^{2}+\omega\right]\right. \\
s k \sigma^{3} L^{3} & =\omega[(1-\omega) d]^{3}+\frac{1-\omega}{2}\left([1-\omega d]^{3}-[1+\omega d]^{3}\right)=d(1-\omega) \omega\left[d^{2}(2(1-\omega)-1)-3\right]
\end{aligned}
$$

Note that $\zeta_{c}<\zeta_{n}<\zeta_{p} \Rightarrow|d|<1$. Since $2(1-\omega)-1<1$ for all $u \in(0,1)$, it follows that $(1-\omega) \omega\left[d^{2}(2(1-\omega)-1)-3\right]<0$. Therefore, $s k<0 \Leftrightarrow d>0 \Leftrightarrow \zeta_{n}-\zeta_{c}>\zeta_{p}-\zeta_{n}$. Thus, $s k<0$ if and only if $\zeta_{n}-\zeta_{c}>\zeta_{p}-\zeta_{n}$ :

$$
\zeta_{n}-\zeta_{c}>\zeta_{p}-\zeta_{n} \Leftrightarrow \log \left(u \frac{\mu_{w}}{1-\beta} \frac{1-h \delta u^{-1}}{1-h \delta}\right)<-\log (u) \Leftrightarrow S(u)=\frac{\mu_{w}}{1-\beta} \frac{u^{2}-h \delta u}{1-h \delta}-1<0
$$


Given the parameter restriction $\mu_{w}<1-\beta$ and the necessary condition for existence of an RSE $u>h \delta$, it follows that $S^{\prime \prime}(u)>0, S(1)<0$ and $S(0)<0$. Therefore, $S(u)<0$ for any $u \in[0,1] . \not{a}$

Derivation of (29). Any solution to the Pareto problem is characterized by the optimal accumulation of $\mathrm{N}$-goods that maximizes the discounted sum of T-production

$$
\max _{\left\{d_{t}\right\} \in \mathcal{C}^{1}} \sum_{t=0}^{\infty} \delta^{t} d_{t}^{\alpha}, \quad \text { st } \quad k_{t+1}=\left\{\begin{array}{cc}
\theta k_{t}-d_{t} & \text { if } t \geq 1 \\
q_{0}-d_{0} & \text { if } t=0
\end{array}, d_{t} \geq 0, q_{o}\right. \text { given }
$$

The Hamiltonian associated with this problem is $H_{t}=\delta^{t}\left[d_{t}\right]^{\alpha}+\lambda_{t}\left[\theta k_{t}-d_{t}\right]$. Since $\alpha \in(0,1)$, the necessary and sufficient conditions for an optimum are

$$
0=H_{d}=\delta^{t} \alpha\left[d_{t}\right]^{\alpha-1}-\lambda_{t}, \quad \lambda_{t-1}=H_{k}=\theta \lambda_{t}, \quad \lim _{t \rightarrow \infty} \lambda_{t} k_{t}=0
$$

Thus, the Euler equation is

$$
\hat{d}_{t+1}=[\delta \theta]^{\frac{1}{1-\alpha}} d_{t}=\theta \hat{\phi} d_{t}, \quad \hat{\phi}:=\left[\delta \theta^{\alpha}\right]^{\frac{1}{1-\alpha}} \quad t \geq 1
$$

To get a closed form solution for $d_{t}$ we replace (46) in the accumulation equation:

$$
k_{t}=\theta^{t-1} k_{1}-d_{0} \sum_{s=0}^{t-2} \theta^{t-s-2}[\delta \theta]^{\frac{s+1}{1-\alpha}}=\theta^{t-1}\left[k_{1}-d_{0} \hat{\phi} \frac{1-\hat{\phi}^{t-1}}{1-\hat{\phi}}\right]=\theta^{t-1}\left[k_{1}-\frac{d_{1}}{\theta} \frac{1-\hat{\phi}^{t-1}}{1-\hat{\phi}}\right]
$$

Replacing (46) and (47) in the transversality condition we get

$$
\begin{aligned}
0 & =\lim _{t \rightarrow \infty} \delta^{t} \alpha\left[d_{t}\right]^{\alpha-1} k_{t}=\lim _{t \rightarrow \infty} \delta^{t} \alpha\left[[\delta \theta]^{\frac{t}{1-\alpha}} d_{0}\right]^{\alpha-1}\left[\theta^{t-1} k_{1}-d_{0} \hat{\phi} \frac{1-\hat{\phi}^{t-1}}{1-\hat{\phi}}\right] \\
& =\frac{\alpha d_{0}^{\alpha-1}}{\theta}\left[k_{1}-d_{0} \hat{\phi} \frac{1}{1-\hat{\phi}}\right] \quad \text { iff } \hat{\phi}<1
\end{aligned}
$$

Since $k_{1}=q_{0}-d_{0}$, the bracketed term equals zero if and only if $\hat{d}_{0}=[1-\hat{\phi}] q_{0}$. The accumulation equation then implies that the unique optimal solution is $\hat{d}_{t}=[1-\hat{\phi}] q_{t}$. $\mathrm{x}$

Derivation of (33). To simplify notation we assume temporarily that there is only one crisis (at time $\tau$ ). It follows that profits and the bailout cost are:

$$
\begin{aligned}
& \pi_{t}=\frac{\alpha}{1-\phi^{l}} \beta y_{t}-\frac{\alpha \phi^{l}}{1-\phi^{l}} \frac{h}{u} y_{t-1}, \quad t \neq\{0, \tau, \tau+1\} \\
& \pi_{0}=\frac{\alpha}{1-\phi^{l}} \beta y_{0}, \quad \pi_{\tau}=0, \quad \pi_{\tau+1}=\frac{\alpha}{1-\phi^{l}} \beta y_{\tau+1}-\frac{\alpha \phi^{c}}{1-\phi^{c}} h y_{\tau}
\end{aligned}
$$




$$
T(\tau)=L_{\tau-1}-\mu p_{\tau} q_{\tau}=\frac{\alpha}{1-\phi^{l}} \frac{h}{u} \phi^{l} y_{\tau-1}-\mu p_{\tau} q_{\tau}=\frac{\alpha}{1-\phi^{l}} \frac{h}{u} \phi^{l} y_{\tau-1}-\mu \frac{\alpha}{1-\phi^{c}} y_{\tau}
$$

Replacing these expressions in welfare function (31) and using the market clearing condition $p_{t} q_{t}\left[1-\phi_{t}\right]=\alpha y_{t}$, we get

$$
\begin{aligned}
W(\tau)= & (1-\alpha) y_{o}+\frac{\alpha \beta y_{o}}{1-\phi^{l}}+\sum_{t=1}^{\tau-1} \delta^{t}\left[\left[(1-\alpha) y_{t}+\frac{\alpha \beta y_{t}}{1-\phi^{l}}-\frac{\alpha \phi^{l} y_{t-1}}{1-\phi^{l}} \frac{h}{u}\right]+\delta^{\tau}\left[(1-\alpha) y_{\tau}+\frac{\mu \alpha y_{\tau}}{1-\phi^{c}}-\frac{\alpha \phi^{l} y_{\tau-1}}{1-\phi^{l}} \frac{h}{u}\right]\right. \\
& +\delta^{\tau+1}\left[(1-\alpha) y_{\tau+1}+\frac{\alpha}{1-\phi^{l}} \beta y_{\tau+1}-\frac{\alpha h \phi^{c}}{1-\phi^{c}} y_{\tau}\right]+\sum_{t=\tau+2}^{\infty} \delta^{t}\left[(1-\alpha) y_{t}+\frac{\alpha \beta}{1-\phi^{l}} y_{t}-\frac{\alpha \phi^{l}}{1-\phi^{l}} \frac{h}{u} y_{t-1}\right. \\
= & \sum_{t \neq \tau} \delta^{t}\left[(1-\alpha) y_{t}+\frac{\alpha}{1-\phi^{l}} \beta y_{t}-\frac{\alpha}{1-\phi^{l}} \frac{\delta h}{u} \phi^{l} y_{t}\right]+\delta^{\tau}\left[(1-\alpha) y_{\tau}+\mu \frac{\alpha}{1-\phi^{c}} y_{\tau}-\frac{\alpha \phi^{c}}{1-\phi^{c}} \delta h y_{\tau}\right] \\
= & \sum_{t \neq \tau} \delta^{t} y_{t}+K^{c} y_{\tau}, \quad K^{c}:=1-\alpha+\mu \frac{\alpha}{1-\phi^{c}}-\frac{\alpha}{1-\phi^{c}} \delta h \phi^{c}=1-\frac{\alpha\left[1-\left(\mu+\mu_{w}\right)\right]}{1-\phi^{c}}
\end{aligned}
$$

Notice that $K_{c}$ can be simplified as follows

$$
K_{c}=\alpha+\frac{\alpha}{1-\phi^{c}}\left(\mu-\left(1-\mu_{w}\right)+\left(1-\mu_{w}\right)-\delta h \phi^{c}\right)=\alpha+\frac{\alpha}{1-\phi^{c}}\left(\left(1-\mu_{w}\right)-\delta h \phi^{c}\right)-\frac{\alpha\left[1-\left(\mu+\mu_{w}\right)\right]}{1-\phi^{c}}
$$

Notice that $\frac{1}{1-\phi^{c}}\left(\left(1-\mu_{w}\right)-\delta h \phi^{c}\right)=\frac{\left(1-\mu_{w}\right)(1-h \delta)-h \delta \mu_{w}}{1-h \delta-\mu_{w}}=\frac{1-h \delta-\mu_{w}}{1-h \delta-\mu_{w}}=1$. Thus, $K_{c}=1-$ $\frac{\alpha\left[1-\left(\mu+\mu_{w}\right)\right]}{1-\phi^{c}}$. The expression for expected welfare in (33) follows by allowing multiple crises to take place.

Derivation of (34). Consider T-output net of bankruptcy costs: $\tilde{y}_{t}=K_{t} y_{t}$, where $K_{t}$ is defined in (33). Notice that $W^{r}=E_{0} \sum_{t=0}^{\infty} \delta^{t} K_{t} y_{t}=E_{0} \sum_{t=0}^{\infty} \delta^{t} \widetilde{y}_{t}$, and $\frac{\tilde{y}_{t}}{\widetilde{y}_{t-1}}$ follows a three-state Markov chain defined by:

$$
\widetilde{T}=\left(\begin{array}{ccc}
u & 1-u & 0 \\
0 & 0 & 1 \\
u & 1-u & 0
\end{array}\right), \quad \widetilde{G}=\left(\begin{array}{c}
g_{1} \\
g_{2} \\
g_{3}
\end{array}\right)=\left(\begin{array}{c}
\left(\theta \phi^{l}\right)^{\alpha} \\
{\left[\theta \phi^{l} \frac{1-\phi^{c}}{1-\phi^{l}}\right]^{\alpha} K_{c}} \\
{\left[\theta \phi^{c} \frac{1-\phi^{l}}{1-\phi^{c}}\right]^{\alpha} \frac{1}{K_{c}}}
\end{array}\right)
$$

To derive $W^{r}$ in closed form consider the following recursion

$$
\begin{aligned}
V\left(\widetilde{y}_{0}, g_{0}\right) & =E_{0} \sum_{t=0}^{\infty} \delta^{t} \widetilde{y}_{t}=\widetilde{y}_{0}+\delta E_{0} V\left(\widetilde{y}_{1}, g_{1}\right) \\
V\left(\widetilde{y}_{t}, g_{t}\right) & =y_{t}+\beta E_{t} V\left(\widetilde{y}_{t+1}, g_{t+1}\right)
\end{aligned}
$$

Suppose that the function $V$ is linear: $V\left(\widetilde{y}_{t}, g_{t}\right)=\widetilde{y}_{t} w\left(g_{t}\right)$, with $w\left(g_{t}\right)$ an undetermined coefficient. Substituting this guess into (51), we get $w\left(g_{t}\right)=1+\delta E_{t} g_{t+1} w\left(g_{t+1}\right)$. Combining 
this condition with (50), it follows that $w\left(g_{t+1}\right)$ satisfies

$$
\left(\begin{array}{l}
w_{1} \\
w_{2} \\
w_{3}
\end{array}\right)=\left(\begin{array}{l}
1 \\
1 \\
1
\end{array}\right)+\delta\left(\begin{array}{ccc}
u & 1-u & 0 \\
0 & 0 & 1 \\
u & 1-u & 0
\end{array}\right)\left(\begin{array}{l}
g_{1} w_{1} \\
g_{2} w_{2} \\
g_{3} w_{3}
\end{array}\right) \Rightarrow \begin{aligned}
& w_{1}=\frac{1+(1-u) \delta g_{2}}{1-(1-u) \delta^{2} g_{2} g_{3}-u \delta g_{1}} \\
& w_{2}=\frac{1+\delta g_{3}-u \delta g_{1}}{1-(1-u) \delta^{2} g_{2} g_{3}-u \delta g_{1}} \\
& w_{3}=\frac{1+(1-u) \delta g_{2}}{1-(1-u) \delta^{2} g_{2} g_{3}-u \delta g_{1}}
\end{aligned}
$$

This solution exists and is unique provided $g_{1} \delta u+g_{2} g_{3} \delta^{2}(1-u)<1$. Equation (34) follows by noting that at time 0 the economy is in the lucky state: $V\left(y_{0}, g_{0}\right)=w_{1} y_{0}^{l}$, and by making the substitution $g_{2} g_{3}=\left(\theta \phi^{l}\right)^{\alpha}\left(\theta \phi^{c}\right)^{\alpha}$.

Proof of Proposition 5.2. The welfare of a risky and a safe economy are given by (32) and (33), respectively. Clearly, if $u=1$, both are equal. Since $W^{s}$ does not depend on $u$, we will prove the proposition by showing that when crises costs are small (i.e., $\mu \rightarrow \beta$ and $\mu_{w} \rightarrow 1-\beta$, so that $\left.k_{c} \rightarrow 1\right)$ the derivative $W_{u}^{r}:=\partial W^{r} /\left.\partial u\right|_{u=1}$ is negative if and only if $\phi^{s}<\phi^{p o}$. Let us denote:

$$
L=1-\left[\theta \phi^{l}\right]^{\alpha} \delta u-\left[\theta^{2} \phi^{l} \phi^{s}\right]^{\alpha} \delta^{2}(1-u), \quad T=\left(1+\delta(1-u)\left[\theta \phi^{l} \frac{1-\phi^{s}}{1-\phi^{l}}\right]^{\alpha}\right)\left(1-\phi^{l}\right)^{\alpha}
$$

The derivatives of $L$ and $T$ evaluated at $u=1$ are:

$$
\begin{aligned}
L_{u} & =-\delta(\theta \phi)^{\alpha}-\alpha \phi^{\prime} \delta(\theta \phi)^{\alpha-1}+[\theta \phi]^{2 \alpha} \delta^{2} \\
T_{u} & =-\alpha \phi^{\prime}[(1-\phi)]^{\alpha-1}-\delta[\theta \phi]^{\alpha}(1-\phi)^{\alpha}=(1-\phi)^{\alpha-1}\left(-\alpha \phi^{\prime}-\delta[\theta \phi]^{\alpha}(1-\phi)\right),
\end{aligned}
$$

where $\phi=\phi^{s}$ and $\phi^{\prime}=\partial \phi^{l} /\left.\partial u\right|_{u=1}$. Since $W^{r}(u)=T / L$, it follows that

$$
\begin{aligned}
\frac{T^{2} W_{u}^{r}}{q_{0}^{\alpha}} & =(D-1)(1-\phi)^{\alpha-1}\left(\alpha \phi^{\prime}+D(1-\phi)\right)+(1-\phi)^{\alpha}\left(D+\alpha \phi^{\prime} \frac{D}{\phi}-D^{2}\right) \\
\frac{T^{2} W_{u}^{r}}{(1-\phi)^{\alpha-1} q_{0}^{\alpha}} & =(D-1)\left(\alpha \phi^{\prime}+D(1-\phi)\right)+(1-\phi) D\left(1+\frac{\alpha \phi^{\prime}}{\phi}-D\right)=\alpha \phi^{\prime}\left(\frac{D}{\phi}-1\right)=\alpha \phi^{\prime}\left(\delta(\theta)^{\alpha} \phi^{\alpha-1}-1\right)
\end{aligned}
$$

where $D=\delta(\theta \phi)^{\alpha}$. Since $\phi<1$ and $\phi^{\prime}<0$, we have that $W_{u}^{r}<0$ if and only if $\delta(\theta)^{\alpha}\left(\phi^{s}\right)^{\alpha-1}>1$. Recall from (30) that the Pareto optimal share is $\phi^{p o}=\left(\theta^{\alpha} \delta\right)^{\frac{1}{1-\alpha}}$. Hence, we can rewrite this condition as $W_{u}^{r}<0$ if and only if $\phi^{s}<\left(\delta \theta^{\alpha}\right)^{\frac{1}{1-\alpha}}=\phi^{p o}$. Since the system is continuous in $u, \mu$ and $\mu_{w}$, the result in the Proposition follows. $\not x$

Derivation of (36). Suppose for a moment that there is only one crisis (at $\tau$ ). Then consumers welfare is

$$
C(\tau)=(1-\alpha) y_{o}+\sum_{t \neq \tau} \delta^{t}(1-\alpha) y_{t}+\delta^{\tau}\left[(1-\alpha) y_{\tau}-T(\tau)\right]
$$


Using $T(\tau)=\frac{\alpha}{1-\phi} \frac{h}{u} \phi^{l} y_{\tau-1}-\mu \frac{\alpha}{1-\phi^{c}} y_{\tau}$ and $y_{\tau}=\left(\theta \phi^{l}\right)^{\alpha}\left[\frac{1-\phi^{c}}{1-\phi^{l}}\right]^{\alpha} y_{t-1}$, it follows that

$$
\begin{aligned}
(1-\alpha) y_{\tau}-T(\tau) & =y_{\tau}\left(1-\alpha-\frac{\alpha}{1-\phi^{c}}\left[\frac{h}{u \theta^{\alpha}}\left[\frac{1-\phi^{c}}{\frac{1}{\phi^{l}}-1}\right]^{1-\alpha}-\mu\right]\right) \\
& =(1-\alpha) y_{\tau}\left(1-\frac{\alpha}{\left(1-\phi^{c}\right)(1-\alpha)}\left[\frac{h}{u \theta^{\alpha}}\left[\frac{1-\phi^{c}}{\frac{1}{\phi^{l}}-1}\right]^{1-\alpha}-\mu\right]\right) \equiv(1-\alpha) y_{\tau} K_{c}^{T}
\end{aligned}
$$

If we allow multiple crises to occur, consumer's welfare is

$$
C^{r}=(1-\alpha) E_{0} \sum_{t=0}^{\infty} \delta^{t} K_{t} y_{t}, \quad K_{t}=\left\{\begin{array}{cc}
1 & \text { if } t \neq \tau_{i} \\
K_{c}^{T} & \text { if } t=\tau_{i}
\end{array}\right.
$$

Following the same steps as in the derivation of (34) we get (36).

\section{B. Model Simulations}

The behavior of the model economy is determined by eight parameters: $u, r, \alpha, \theta, h, \beta$, $\mu_{w}$ and $\mu$. We will set the probability of crisis $1-u$, the world interest rate $r$ and the share of $\mathrm{N}$-inputs in T-production $\alpha$ equal to some empirical estimates. Then, given the values of $u, r$ and $\alpha$, we determine the feasible set for the degree of contract enforceability $h$ and the index of total factor productivity in the N-sector $\theta$ such that both an RSE and an SSE exist. The values of $\beta, \mu_{w}$ and $\mu$ are irrelevant for the existence of equilibria.

In a panel of 39 MECs studied in Tornell and Westermann (2002), the probability of a crisis in a given period ranges from $5 \%$ to $9 \%$. The interest rate $r$, is set to the average US interest rate from 1980:1 to 1999:4, which equals 0.075. A survey of Mexican manufacturing firms suggests a conservative value for $\alpha$ equal to $35 \%$. We then choose $\beta, \theta$ and $h$ so that: (i) both an RSE and an SSE exist for the range $u \in[0.91,1]$, and (ii) we obtain plausible values for the growth rates along a safe economy and along a lucky path. In the baseline case: $h=0.76, \theta=1.65, \beta=0.8$ and $u=0.95$. These parameters imply a safe GDP growth rate of $\left(1+\gamma^{s}\right)=(1-\beta)^{\alpha} \frac{\theta}{1-h \delta}=3.8 \%$ and a lucky GDP growth rate of $\left(1+\gamma^{l}\right)=(1-\beta)^{\alpha}\left(\frac{\theta}{1-h \delta u^{-1}}\right)^{\alpha}=8.7 \%$. By comparison, the average growth rate of India over the period is $5.14 \%$ and that of Thailand is $8.14 \%$.

We choose the financial distress costs of crises $l^{d}=1-\frac{\mu_{w}}{1-\beta}$ so that the cumulative decrease of GDP during a crisis episode is $13 \%$, which is the mean value in the sample considered by Tornell and Westermann (2002). In the model, the cumulative decrease in GDP growth 
during a crisis episode is $\left(1+\gamma^{c r}\right)^{2}=\left[\frac{\mu_{w}}{1-\beta}\right]^{\alpha}\left(\theta^{2} \phi^{l} \phi^{s}\right)^{\alpha}$. Using the baseline case $h=0.76$, $\theta=1.65$, and $\alpha=0.35$ we get that $\left(1+\gamma^{c r}\right)^{2}=(1-0.13)$ if $\left[\frac{\mu_{w}}{1-\beta}\right]=0.45$. Thus, we set conservatively $l^{d}=0.7$. In the baseline case, the level of bankruptcy costs is free.

Finally, in order for the welfare measures to be bounded, the expected discounted sum of tradable production has to be finite. In the safe economy this requires $\delta\left(\theta \phi^{s}\right)^{\alpha}<1$. In the risky economy: $\left[\theta \phi^{l}\right]^{\alpha} \delta u+\left[\theta^{2} \phi^{l} \phi^{c}\right]^{\alpha} \delta^{2}(1-u)<1$. These two conditions impose an upper bound on $\alpha .^{32}$ In particular, they hold if $\alpha<0.6$. Summing up:

\begin{tabular}{|c|c|c|}
\hline Parameters & baseline case & range of variation \\
\hline N-sector productivity & $\theta=1.6$ & \\
\hline Enforceability of contracts & $h=0.76$ & {$[0.6,0.8]$} \\
\hline Intensity of N-inputs in T-production & $\alpha=0.35$ & {$[0.2,0.6]$} \\
\hline Cash flow/sales in N-sector & $1-\beta=20 \%$ & \\
\hline Financial distress costs & $l^{d}=70 \%$ & {$[30 \%, 99 \%]$} \\
\hline Bankruptcy costs & $l^{b}=100 \%$ & {$[30 \%, 100 \%]$} \\
\hline Probability of crisis & $1-u=0.05$ & {$[0,0.9]$} \\
\hline Discount factor & $\delta=0.925$ & \\
\hline
\end{tabular}

\section{References}

[1] Barro, R., G. Mankiw and X. Sala-i-Martin, 1995, "Capital Mobility in Neoclassical Models of Growth," American Economic Review, 85,103-115.

[2] Bekaert, G., C. Harvey, and R. Lundblad, 2001, "Does Financial Liberalization Spur Growth?" NBER WP 8245.

[3] Bernanke, B., M. Gertler and S. Gilchrist, 2000, "The Financial Accelerator in a Quantitative Business Cycle Framework" in Handbook of Macroeconomics, Taylor and Woodford eds.

\footnotetext{
${ }^{32}$ Notice that the interior condition for the pareto optimal share, $\phi^{p o}=\left[\theta^{\alpha} \delta\right]^{\frac{1}{1-\alpha}}<1$ is sufficient for all boundness conditions if $\phi^{l}<\phi^{p o}$. This condition is equivalent to an upper bound on $\alpha: \bar{\alpha}=\frac{\log (1+r)}{\log (\theta)}$.
} 
[4] Chari, A. and P. Henry, 2002, "Capital Account Liberalization: Allocative Efficiency or Animal Spirits?" NBER WP 8908.

[5] Cole, H. and T. Kehoe, 2000, "Self-Fulfilling Debt Crises," Review of Economic Studies, 67, 91-116.

[6] Fatas, A. and I. Mihov, 2002, "The Case for Restricting Fiscal Policy Discretion," CEPR Discussion Paper No. 3277.

[7] Francois, P. and H. Lloyd-Ellis, 2003, "Animal Spirits through Creative Destruction," American Economic Review, 93(4): 530-550.

[8] Gaytan, A. and R. Ranciere, 2002, "Banks, Liquidity Crises and Economic Growth," unpublished.

[9] Gourinchas, P., O. Landerretche and R. Valdes, 2002, "Lending Booms, Latin America and the World," Economia Vol. 1, 2.

[10] Gourinchas, P. and O. Jeanne, 2002, "The Elusive Benefits of International Financial Integration," unpublished.

[11] Imbs, J., 2002, "Volatility, Growth and Aggregation," unpublished.

[12] Jovanovic, B., 2002, "Asymmetric Cycles," unpublished.

[13] Juglar, C., 1862, Des Crises Commerciales et Leur Retour Periodique en France, en Angleterre et aux Etats-Unis, Guillaumin Editeur, Paris.

[14] Juglar, C., 1863, "Crises Commerciales" in Dictionaire Generale de la Politiques, Berger-Levrault Editeur.

[15] Kaminsky, G. and S. Schmukler, 2002, "Short-Run Pain, Long-Run Gain: The Effects of Financial Liberalization," unpublished.

[16] Konrad, K., 1992, Risikoproduktivität, Contemporary Studies in Economics, Springer, Heidelberg, Berlin. 
[17] Kraay, A, and D. Kaufman, 2003, "On Growth without Governance," Economia, 3(1), 169-229.

[18] Levine, R., 2001, "International Financial Liberalization and Economic Growth," Review of International Economics, 9-4.

[19] Levine, R. and Renelt, 1992, "A Sensitivity Analysis of Cross-Country Growth Regression," American Economic Review; 82(4): 942-63.

[20] Loayza, N. and R. Ranciere, 2001, "Financial Development, Financial Fragility and Growth," unpublished.

[21] Matsuyama, K., 1999, "Growing Through Cycles," Econometrica, 335-337.

[22] Newey, D. and K. West, 1987, "A Simple, Positive Semi-definite, Heteroskedasticity and Autocorrelation Consistent Covariance Matrix," Econometrica, 55(3), 703-08.

[23] Obstfeld, M., 1994, "Risk-Taking, Globalization, and Growth," American Economic Review, 84, 1310-1329.

[24] Ollivier, J., 2000, "Growth-Enhancing Bubbles," International Economic Review, 41, pages $133-151$

[25] Prasad, E., K. Rogoff, S. Wei and A. Kose, 2003, "Effect of Financial Globalization on Developing Countries: Some Empirical Evidence," IMF.

[26] Rajan, R. and L. Zingales, 1998, "Financial Dependence and Growth," American Economic Review, vol.. 88, pp 559-586.

[27] Ramey, V. and Ramey, 1995, "Cross-Country Evidence on the Link between Volatility and Growth," American Economic Review 85(5), 1138-51.

[28] Rodrik, D., 1998, "Who Needs Capital-Account Convertibility?" Princeton Studies in International Finance.

[29] Schneider, M. and A. Tornell, 2003, "Balance Sheet Effects, Bailout Guarantees and Financial Crises," Review of Economic Studies, forthcoming. 
[30] Schumpeter J., 1934, The Theory of Economic Development, Harvard University Press.

[31] Silverman, B. W., 1986, Density Estimation for Statistics and Data Analysis, Chapman \& Hall.

[32] Sinn, H. W., 1986, "Risiko als Produktionsfaktor," Jahrbücher für Nationalökonomie and Statistik 201, pp. 557-571.

[33] Tirole, J., 2002a, Financial Crises, Liquidity and the International Monetary System, Princeton University Press.

[34] Tirole, J., 2002b, "Inefficient Foreign Borrowing: a Dual-and-common Agency Perspective," unpublished.

[35] Tornell, A. and F. Westermann, 2002, "Boom-Bust Cycles: Facts and Explanation," IMF Staff Papers, 49.

[36] Tornell, A. and F. Westermann, 2003, "Credit Market Imperfections in Middle Income Countries," NBER WP 9737.

[37] Veldkamp, L., 2002, "Slow Boom, Sudden Crash," INSEAD mimeo.

[38] Ventura, J., 2002, "Bubbles and Capital Flows," NBER WP 9304. 